\title{
Structural Studies on Alkylisocyanate Polymers by Thermal Degradation Tandem Mass Spectrometry
}

\author{
Tapan K. Majumdar, Marcos N. Eberlin,* and R. Graham Cooks \\ Department of Chemistry, Purdue University, West Lafayette, Indiana, USA
}

Mark M. Green, Beth Muñoz, and Mike P. Reidy

Department of Chemistry, Polytechnic University, Brooklyn, New York, USA

\begin{abstract}
Homopolymers and copolymers of alkylisocyanates having n-hexyl, 2,6-dimethylheptyl, 3,7-dimethyloctyl, and (2,2-dimethyl-1,3-dioxolan-4-yl)methyl substituents underwent thermal degradation in the course of desorption clectron ionization to yield trimers and monomers that were characterized in situ by tandem mass spectrometry. The trimers were trisubstituted cyanuric acids, the protonated molecules displaying a characteristic series of alkene eliminations on collision-induced dissociation to yield protonated cyanuric acid, $\mathrm{m} / \mathrm{z}$ 130. Confirmation of the identity of the pyrolysates was obtained by using two types of $\mathrm{MS}^{3}$ experiments: the reaction intermediate scan and the two-dimensional familial scan. The ion chemistry of the trimers and of the protonated monomer, the alkylisocyanate, was elucidated. Among the many interesting fragmentation processes undergone by the ionized trimers were $\alpha$ and $\beta \mathrm{C}-\mathrm{C}$ bond cleavages and charge-remote fragmentations, which provided information on branching in the alkyl substituent. The dioxolane-containing substituent showed unique ion chemistry. The monomer distribution in the copolymers was deduced from the abundances of the various protonated trimers. The distribution was found to be random in all copolymers except that containing the dioxolane substituent. (] Am Soc Muss Spectrom 1991, 2, 130-148)
\end{abstract}

$P$ olyisocyanates [1], also known as N-substituted 1-nylons, are linear high molecular weight polymers $[2,3]$ having liquid-crystalline properties [4]. In this study we investigate the application of tandem mass spectrometry (MS/MS) to these liquid crystal polymers. This is appropriate because mass spectrometry has been shown to be useful in examining the polyisocyanates [5] and, in general, is seeing gradually increasing use as a tool for polymer characterization $[6-8]$ as a result of the lifting of the principal limitations of the technique through advances in ionization methods [9-11] and extensions in mass range [12-15]. The present study has three major objectives: (1) to investigate the usefulness of pyrolysis/MS/MS in identifying the products of thermal degradation of polyisocyanates, (2) to investigate the ion chemistry of the polyisocyanale pyrolysates, and (3) to establish whether mass spectrometric methods are useful in determining the distribution of monomers in copolymers.

*On leave from Universidade Estadual de Campinas, C.P. 6154, 13081, Campinas, SP, Brazil.

Address reprint requests to $R$. Graham Cooks, Department of Chemistry, Purdue University, West Lafayette, IN 47907.
Pyrolysis, when coupled with spectroscopic techniques, is a generally useful approach to the analysis of polymers and other complex nonvolatile organic materials. Since the introduction of pyrolysis/mass spectrometry by Zemany [16], it has been applied extensively in polymer analysis. Commonly, gas chromatography combined with mass spectrometry is used to characterize pyrolysates [17-19] although the method has obvious limitations. In other experiments, pyrolysis of nonvolatile samples is followed by immediate ionization of the pyrolysate and mass analysis of the resulting gas-phase ions $[6-8,16-22]$. Three methods are commonly used in pyrolysis/mass spectrometry: (1) Curie-point pyrolysis [23], which involves rapid inductive heating $\left(10^{2}-10^{4} \mathrm{~K} / \mathrm{s}\right)$, (2) pyrolysis by means of laser irradiation [24], and (3) pyrolysis induced by slower resistive heating of a sample in a direct insertion probe or furnace pyrolyzer [25]. Two versions of the last method, desorption chemical ionization (DCI) and desorption electron ionization (DEI) [26], utilize relatively rapid heating of a sample placed on a thin wire that is introduced directly into the ionization chamber of an electron impact or chemical ionization source. This procedure, 
like the closely related particle impact desorption methods of ionization [27], can result in vaporization of thermally labile molecules without thermal degradation. For example, laser desorption Fourier-transform mass spectrometry has been applied successfully to determine the molecular weight distributions and copolymer compositions of a series of methylmethacrylate/butylacrylate, methylmethacrylate/styrene, and poly(ethylene glycol)/poly(propylene glycol) copolymers [28].

Tandem mass spectrometry provides enhanced capabilities for elucidating molecular structures, especially for compounds present in mixtures $[29,30]$. The combination of desorption ionization methods with MS/MS has proven of value in biopolymer research, especially peptide sequencing [31, 32], and MS/MS may also have much to offer in structural characterization of other types of polymers. This is indicated by the studies of Lattimer et al. [6], who used MS/MS combined with fast atom bombardment to study polyglycois and found the technique useful for direct analysis of the structures of individual components in mixtures of oligomers. Similarly, Montaudo and $\mathrm{CO}-$ workers $[20,21]$ used MS/MS in structural studies of mixtures of pyrolysis products of polyamides.

An extension of the MS/MS concept is embodied in $\mathrm{MS}^{3}$ experiments, which employ three stages of mass analysis [33]. Two types of $\mathrm{MS}^{3}$ experiments are employed in this study and are implemented by using a pentaquadrupole mass spectrometer [34]. In the first type, the reaction intermediate scan, intermediate ions connecting a specific parent ion and a terminal fragment ion are recorded [35]. In the second type, the familial scan, the parents and daughters of a particular mass-selected ion are recorded in the form of a two-dimensional mass spectrum [35]. These are new capabilities in mass spectrometry and it is clearly of interest to establish their utility.

\section{Experimental}

Mass spectra and MS/MS experiments were recorded by using a Finnigan TSQ 4500 mass spectrometer. Solid samples were placed on a rhenium wire filament of a direct exposure probe or in a glass vial in a direct insertion probe for introduction into the ion source of the mass spectrometer. Typical sample sizes were approximately $1 \mu \mathrm{g}$ for DEI and DCI mass spectra and $10 \mu \mathrm{g}$ for MS/MS experiments. The ion source temperature was $190^{\circ} \mathrm{C}$ and background pressure in the ion source was $3 \times 10^{-8}$ torr. Pyrolysis of the polymers was carried out within the ion source of the mass spectrometer by heating the probe from $20^{\circ} \mathrm{C}$ to $400{ }^{\circ} \mathrm{C}$ at a rate of $100{ }^{\circ} \mathrm{C} / \mathrm{s}$. The instrument was scanned during the entire temperature ramp. Pyrolysates appeared within the temperature range $200-400{ }^{\circ} \mathrm{C}$. The source pressure during DEI was approximately $2 \times 10^{-7}$ torr. The pyrolysates were ionized either by $15-\mathrm{eV}$ or $70-\mathrm{eV}$ DEI or by DCI by using reagent ions generated from ammonia, isobutane, or methane reagent gases. The chemical ionization $(\mathrm{Cl})$ gas pressure in the ion source was 0.5 torr. The quadrupole mass analyzer was scanned from 100 $\mathrm{u}$ to $600 \mathrm{u}$ at a rate of $1000 \mathrm{u} / \mathrm{s}$ during the collection of $\mathrm{DEI}$ and DCl mass spectra. Fragmentation of the ionized pyrolysates was investigated with MS/MS by using DCI for the production of protonated and other adduct ions and DEI for the formation of radical cations. Parent ions, mass-selected by using the first quadrupole (Q1), were collided with argon collision gas at $20 \mathrm{eV}$ and a pressure of 2.0 mtorr (multiple collision conditions) in the second quadrupole (Q2) to generate daughter spectra, which were recorded by scanning the third quadrupole (Q3). Parent spectra were recorded under the same conditions.

Reaction intermediate and familial scans were recorded by using a custom-built pentaquadrupole instrument [35]. About $0.5 \mathrm{mg}$ of the solid sample was introduced via a direct insertion probe, which was heated from an initial temperature of $35{ }^{\circ} \mathrm{C}$ to the final temperature of $180^{\circ} \mathrm{C}$ at a rate of $120^{\circ} \mathrm{C} / \mathrm{min}$ during pyrolysis. The spectra were acquired at the final temperature. The background pressure in the ion source was $2 \times 10^{-7}$ torr and the maximum indicated sample pressure during pyrolysis was $6 \times 10^{-5}$ torr. The pyrolysates were ionized by $25-\mathrm{eV}$ electron impact. For the reaction intermediate scans, the parent ions were mass-selected by $Q 1$, and the fifth quadrupole (Q5) was set to select a specific fragment ion of interest while scanning Q3. For the familial scan, Q3 was set at a particular mass-to-charge ratio value while scanning both $Q 1$ and $Q 5$ to produce a two-dimensional output. Argon was used as collision gas in both regions at nominal pressures $1 \times 10^{-5}$ torr and $3 \times 10^{-5}$ torr (as measured by remote ion gauges) for the second (Q2) and fourth (Q4) quadrupoles, respectively. The quadrupoles were operated at offset voltages, relative to the grounded ion source, of $Q 1=$ $-10 \mathrm{~V}, \mathrm{Q} 2=-4 \mathrm{~V}, \mathrm{Q} 3=-5 \mathrm{~V}, \mathrm{Q} 4=-8 \mathrm{~V}$, and $\mathrm{Q} 5=-5 \mathrm{~V}$. The $\mathrm{MS}^{3}$ spectra were recorded by scanning the quadrupoles at a rate of $2 \mathrm{u} / \mathrm{s}$ using a custom-built $\mathrm{MS}^{3}$ data system that employed a Keithley Series 500 measurement and control system, a Zenith Z-200 PC, and software written in the " $\mathrm{C}$ " language [35].

Copolymers were synthesized from mixtures containing two monomers in various mole ratios: Polymer-IV was synthesized from $n$-hexylisocyanate and 2,6-dimethylheptylisocyanate in the mole ratio 63:37, Polymer-V from a 50:50 mole ratio of 2,6-dimethylheptylisocyanate and its homologue 3,7-dimethyloctylisocyanate, and Polymer-VI from $n$-hexylisocyanate and (2,2-dimethyl-1,3-dioxolan-4-yl)methylisocyanate in the mole ratio 88:12 [36, 37]. The various polyisocyanates were synthesized by following detailed procedures discussed in the Ph.D. theses of M. P. Reidy 
Table 1. Direct pyrolysis mass spectra of Polymer-I, obtained with different ionization methods ${ }^{a}$

\begin{tabular}{|c|c|c|c|c|c|}
\hline \multirow[b]{2}{*}{$m / z$} & \multicolumn{2}{|c|}{ DEl methods } & \multicolumn{3}{|c|}{ DCl methods } \\
\hline & $70 \mathrm{eV}$ & $15 \mathrm{eV}$ & $\overline{\mathrm{NH}_{3}}$ & i-butane & $\mathrm{CH}_{4}$ \\
\hline 399 & - & - & 36 & - & - \\
\hline 382 & 5 & 17 & 100 & 100 & 100 \\
\hline 381 & 1 & 4 & - & - & - \\
\hline 366 & - & - & - & - & 4 \\
\hline 352 & 3 & 3 & - & - & 1 \\
\hline 338 & 1 & 2 & - & - & 1 \\
\hline 324 & 2 & 3 & - & - & - \\
\hline 311 & $\mathbf{3}$ & 3 & - & - & - \\
\hline 298 & 100 & 100 & - & - & - \\
\hline 281 & 3 & 6 & - & - & - \\
\hline 256 & 2 & 1 & - & - & - \\
\hline 242 & 3 & 2 & - & - & - \\
\hline 228 & 5 & 1 & - & - & - \\
\hline 214 & 5 & - & - & 15 & - \\
\hline 158 & 1 & - & - & - & - \\
\hline 144 & 2 & - & - & - & - \\
\hline 130 & 7 & - & - & - & - \\
\hline 128 & 1 & - & - & 2 & 44 \\
\hline 112 & 2 & 2 & - & - & - \\
\hline
\end{tabular}

${ }^{3}$ Isotopic peaks and ions less than $1 \%$ in relative abundance are not reported.

and B. Muñoz (Polytechnic University, 1990). The synthesis of poly(2,6-dimethylheptylisocyanate) and poly(2,2-dimethyl-1,3-dioxolan-4-yl)methylisocyanate and their copolymers with $n$-hexylisocyanate has appeared in the literature [36, 37].

\section{Results and Discussion}

\section{Homopolymers - Major Pyrolysis Products and Fragmentation Pathways}

The pyrolysis mass spectra of poly(n-hexyl)isocyanate (Polymer-I) display $m / z 382$ as the highest mass ion under DEI conditions and as the most abundant ion under DCI (Table 1), which suggests that this ion represents an ionized form of the predominant pyrolysis product. The daughter spectrum of ion $m / z 382$ shows major fragments at $m / z 298,214$, and 130 (Table 2), ions which appear to arise from $\mathrm{m} / \mathrm{z} 382$ by sequential loss of molecules of hexene $\left(\mathrm{C}_{6} \mathrm{H}_{12}, 84 \mathrm{u}\right)$. This reaction sequence is clearly revealed in the reaction intermediate spectrum [35] (Figure 1), which shows only the ions $m / z 298$ and 214 as intermediates of significant abundance connecting ion $m / z 382$ with the fragment $m / z 130$. The two-dimensional familial scan, acquired by selecting ion $m / z 130$ as the intermediate, also confirms this fragmentation pathway, as well as allowing structural assignments for these ions. This spectrum (Figure 2) shows parent ions, $m / z 382,298$, and 214 , corresponding to the successive losses of hexene units. Since each of the parent ions generates the same set of daughter ions, $m / z 87,70$, and 44 , when they fragment via $m / z 130$ to lower-mass ions, it is clear that each parent produces an identical product $m / z$ 130. The set of fragments displayed by ion $m / z 130$ suggests it to be protonated cyanuric acid, and it is therefore concluded that the individual parent ions are $n$-hexylated forms of this ion.

In order to confirm the structure of ion $m / z$ 130, a daughter spectrum of protonated cyanuric actd was recorded by using an authentic sample of this compound. The similarity of this spectrum with the daughter spectrum of $\mathrm{m} / z 130$ generated by pyrolysis of Polymer-I (Figure 3 ) confirms that they indeed have the same structure. The fragmentation pathway proposed for this ion is shown in Scheme $I$.

From the above information one can conclude that the principal pyrolysis product of Polymer-I is the neutral trimer which, upon DCI and DEI, yields the protonated trimer $[\mathrm{M}+\mathrm{H}]^{+}$at $m / z 382$ and, under DEI conditions, a minor amount of the radical cation of the trimer, $\mathrm{M}^{+}$at $m / z 381$. The use of ammonia as reagent gas leads, in addition to $\left[\mathrm{M}+\mathrm{H}^{+}\right.$, to an $\left[\mathrm{M}+\mathrm{NH}_{4}\right]^{+}$adduct at $m / z$ 399. Formation of the protonated trimer in greater abundance than the molecular ion during DEI is due to self-protonation, which is probably a result of the high local pressure of the pyrolysate in the ion source.

The protonated and the radical cation forms of the molecular ion of the $n$-hexylisocyanate trimer fragment principally by a convergent route (Scheme I) that involves loss of their $n$-hexyl groups $\left(R_{1}\right)$. The proposed mechanism for loss of the stable hexenyl radical from the trimer radical cation, a process that must involve transfer of two hydrogens from the leaving alkyl group, is also shown in Scheme I.

Confurmation of these assignments, as well as further detail of the ion chemistry of the pyrolysate, is available by examination of the daughter and parent ion spectra of the major fragment ions. The hexene elimination process is clearly seen in the daughter 
Table 2. MS/MS spectra of the major ions of Polymer- $I^{a}$

\begin{tabular}{|c|c|c|}
\hline Selected ion $\mathrm{m} / \mathrm{z}$ & Daughter lons $\mathrm{m} / \mathrm{z}$ (\% relative abundance) & Parent ions $m / z$ (\% relative abundance) \\
\hline $399^{b}$ & $382(100), 298(84), 214(45), 130(13)$ & None observed \\
\hline 382 & $\begin{array}{l}298(15), 214(40), 130(100), 128(16), 85(31) \\
59(1), 57(6), 43(11)\end{array}$ & $399(100)^{\mathrm{b}}$ \\
\hline $381^{\mathrm{C}}$ & $\begin{array}{l}298(100), 256(3), 242(3), 228(3), 214(62) \\
144(5), 130(88), 128(3), 85(5), 70(4), 43(3)\end{array}$ & None observed \\
\hline $311^{\mathrm{C}}$ & $\begin{array}{l}282(5), 266(18), 255(14), 241(14), 228(62) \\
158(28), 144(100), 113(18), 87(5), 85(53) \\
70(6), 59(11), 57(37), 43(24)\end{array}$ & $381(100), 353(5)$ \\
\hline $298^{c}$ & $\begin{array}{l}256(1), 214(25), 144(1), 130(100), 128(1) \\
87(8), 85(8), 70(1), 59(2), 57(7), 43(12)\end{array}$ & $382(100)$ \\
\hline $256^{d}$ & $\begin{array}{l}214(7), 179(2), 172(33), 144(1), 130(100), 128(3), \\
93(3), 87(17), 85(8), 70(2), 59(3), 57(5), 43(32)\end{array}$ & $382(100)$ \\
\hline $228^{d}$ & $\begin{array}{l}144(100), 128(1), 101(5), 87(10), 85(3), 70(2) \\
59(2), 57(45), 44(12), 43(45)\end{array}$ & $\begin{array}{r}382(100), 366(18) \\
352(34), 311(97)\end{array}$ \\
\hline $214^{d}$ & $\begin{array}{c}130(45), 87(30), 85(8), 70(8), 59(3), 57(15) \\
44(30), 43(100), 41(2)\end{array}$ & $382(100), 352(3), 298(23)$ \\
\hline 184 & $\begin{array}{l}142(1), 128(6), 85(34), 57(100), 43(65), 41(10) \\
29(4), 27(3)\end{array}$ & None observed \\
\hline $158^{d}$ & $\begin{array}{l}130(18), 87(14), 72(1), 70(7), 59(100), 57(1) . \\
44(62), 43(5), 42(5)\end{array}$ & $\begin{array}{l}382(70), 352(4), 311(21) \\
298(40), 242(100), 212(26)\end{array}$ \\
\hline $144^{d}$ & $87(15), 70(12), 59(3), 68(94), 57(6), 44(100)$ & $\begin{array}{l}382(50), 352(30), 312(13) \\
311(24), 228(100)\end{array}$ \\
\hline $130^{\circ}$ & $87(20), 70(18), 44(100)$ & $\begin{array}{c}382(15), 366(1), 352(2), 298(100) \\
256(1), 242(1), 214(5), 184(1)\end{array}$ \\
\hline 128 & $\begin{array}{l}127(3), 112(5), 98(2), 85(5), 84(10), 70(21) \\
59(7), 57(34), 43(100)\end{array}$ & $382(100), 298(8), 242(1)$ \\
\hline
\end{tabular}

aConditions: Isobutane DCI (unless otherwise noted), 20-eV collisions on Argon $(2$ mtorr).

Ammonia DCl is used.

c 15 -eV DEl is used.

TO-OV DEI is used.

spectra of ions $m / z 298$ and 214 (Table 2). The parent spectra of all the major ions show the protonated trimer, $m / z 382$, as their highest-mass precursor ${ }_{r}$ and their daughter spectra yield either $m / z 144$ or $\mathrm{m} / z$ 130.

The formation of the cyclic trimer is also observed in the direct pyrolysis mass spectra of poly (2,6-dimethylheptyi)isocyanate (Polymer-II) as $[\mathrm{M}+\mathrm{H}]^{+}(\mathrm{m} / \mathrm{z}$ 508), $\mathrm{M}^{+-}(m / z 507)$, and in the case of $\mathrm{NH}_{3} \mathrm{DCl}$, $\left[\mathrm{M}+\mathrm{NH}_{4}\right]^{+}(m / z 525)$ (Table S-1). The fragmentation of ion $\mathrm{m} / \mathrm{z} 508$ by sequential eliminations of the

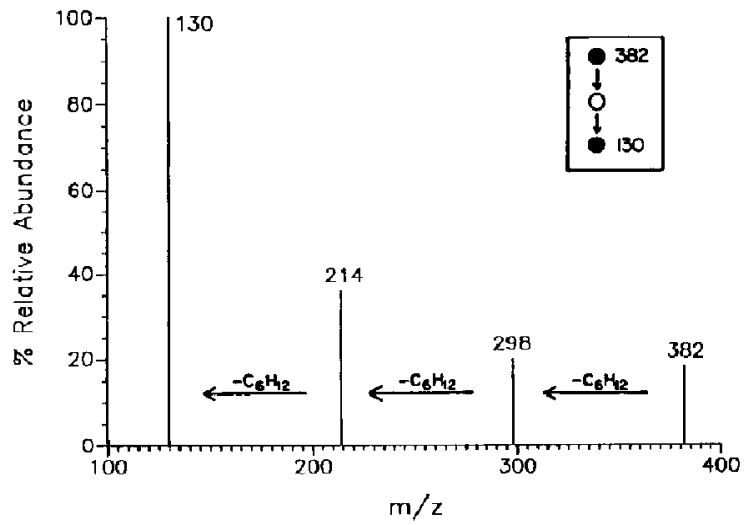

Figure 1. $\mathrm{MS}^{3}$ reaction intermediate spectrum of the protonated trimer from Polymer-I. 2,6-dimethylheptyl groups $\left(R_{2}\right)$ as nonene (126 u) is responsible for the abundant ions at $m / z 382,256$, and 130 in the mass spectrum. This fragmentation sequence, familiar from Scheme $I$, is also evident in its daughter spectrum. The reaction intermediate spectrum (not reproduced since it matches that discussed below for Polymer-IV) clearly shows that the fragment ions $\mathrm{m} / z 382$ and 256 are the intermediates that connect the ions $m / z 508$ and 130 . The isobaric

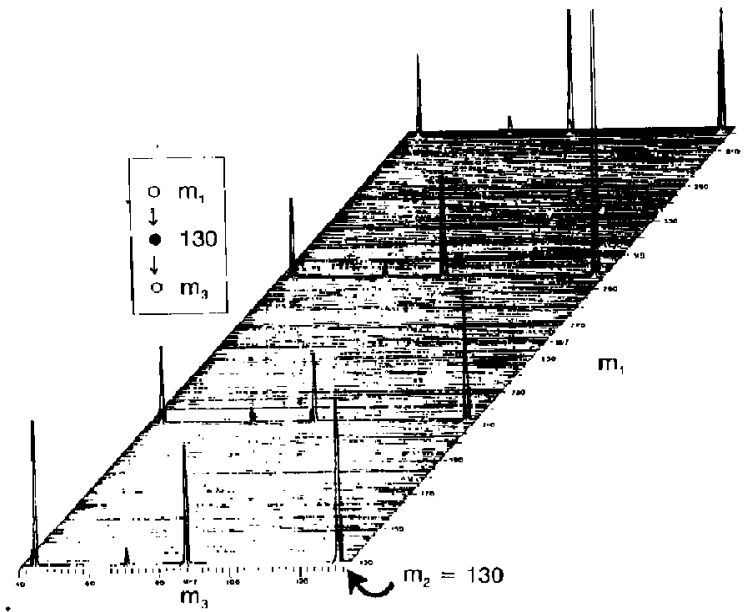

Figure 2. $\mathrm{MS}^{3}$ two-dimensional familial scan from Polymer-I. 
A
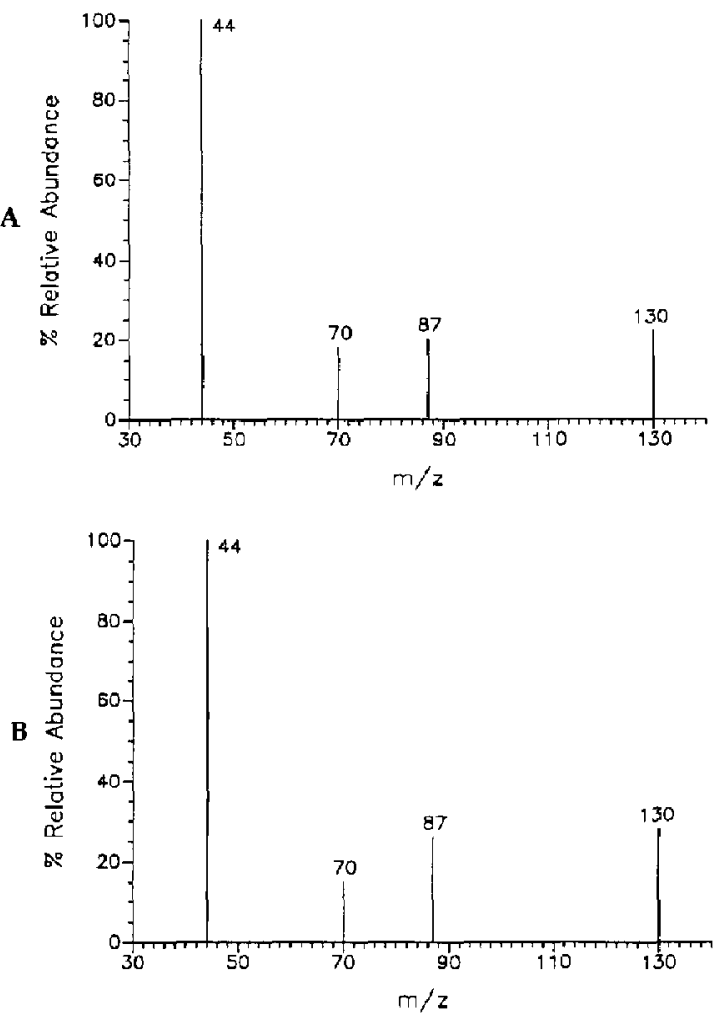

Figure 3. (a) MS/MS daughter spectrum of $m / z 130$ from Polymer-I; (b) MS/MS daughter spectrum of protonated cyanuric acid.

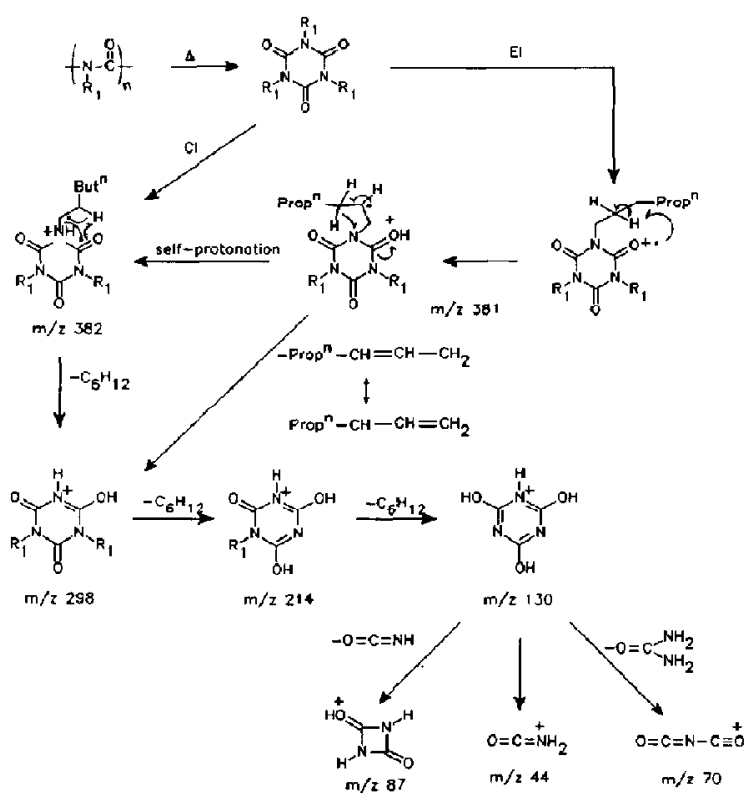

Scheme I<smiles>CCn1c(=O)n(CC)c(=O)n(CC)c1=O</smiles>

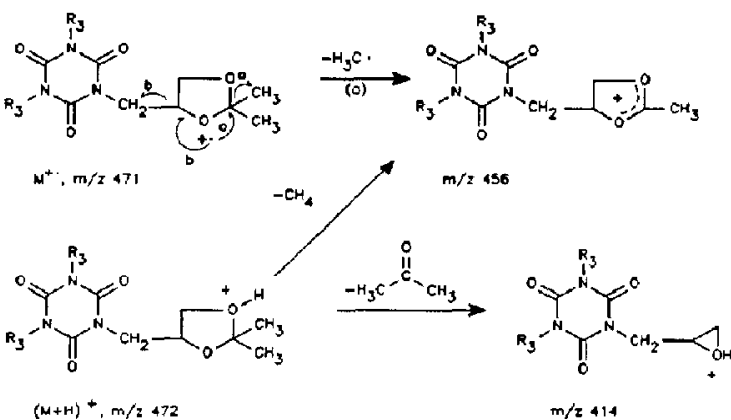

Scheme II

relationship between ions $\mathrm{m} / \mathrm{z} 382$ produced from Polymer-I and Polymer-II is confirmed by their different daughter spectra (Tables 2 and S-2).

A significant amount of the protonated trimer of poly(2,2-dimethyl-1,3-dioxolan-4-yl) methylisocyanate (Polymer-III) is observed under DCI conditions, at $m / z 472$ (Table S-3). Under DEI conditions, however, the ionized forms of the trimer are not observed. A major peak in the DEI mass spectrum $(\mathrm{m} / \mathrm{z}$ 456) corresponds to the loss of a methyl radical from the molecular radical cation, or to the loss of methane from the protonated trimer. This type of fragmentation (Scheme II) is expected to be highly favored in the (2,2-dimethyl-1,3-dioxolan-4-yl)methyl substituent $\left(R_{3}\right)$ [43] and it accounts for the absence of molecular ions. Another fragmentation expected to be favored involves loss of acetone and is also shown in Scheme II.

Singly or in combination, these characteristic fragmentation processes (loss of 15 or 16 and $58 \mathrm{u}$ ) and also loss of $R_{3}$ as nonene (114 u) are responsible for the majority of the observed fragment ions (Scheme S-I). Parent spectra of the major fragment ions (Table S-4) typically show either the protonated trimer ion $m / z 472$ or the ion $m / z 456$ as their precursors. Daughter spectra of ions $\mathrm{m} / \mathrm{z} 472$ and $\mathrm{m} / \mathrm{z} 456$ are decidedly different, as expected from the argument that charge localization occurs on the cyanuric acid in the former and in the side chain of the latter ion.

Another consequence of the favored modes of fragmentation just discussed is that the characteristic alkene elimination sequence is displayed only weakly in Polymer-III, as seen by the low abundance of the protonated cyclic dealkylated trimer, ion $m / z$ 130. In order to check the influence of the charge-stabilizing dioxolane group on the fragmentation behavior of this trimer, 1,3,5-tris(2-hydroxyethyl)cyanuric acid was chosen as an analogue of this compound. Its DEI (70 
$\mathrm{eV}$ ) and isobutane DCI mass spectra (Figure S-1) show production of the protonated molecular ion and complete absence of the $m / z 130$ fragment ion. The daughter spectrum of $[\mathrm{M}+\mathrm{H}]^{+}$(Figure S-1c) also fails to show any ion $m / z$ 130. These and other similarities between the pyrolysis mass spectra of Polymer-III (Table S-3) and 1,3,5-tris(2-hydroxyethyl)cyanuric acid (Figure S-1) confirm that the oxygenated side chain is responsible for the distinctive fragmentation pathway of the trimer derived from Polymer-III.

The MS/MS parent spectrum of the ion $m / z 101$ (Table S-4), a very abundant ion in the DEI spectrum from Polymer-III, does not display any precursors. Its greatly decreased abundance in the DCI mass spectra implies that it is not an ionized form of a pyrolysis product and that it is probably generated by rapid fragmentation of the trimer radical ion in the ion source (Scheme II), as is also the case for ion $\mathrm{m} / \mathrm{z}$ 456. Although the ion $m / z 101$ is expected to be less stable than ion $m / z 456$, its high relative abundance may be due in part to the formation of the more stable complementary radical product.

Carbon-Carbon bond cleavages. The ion $m / z$ 311, present in the mass and MS/MS spectra of Polymer-I (Tables 1 and 2), appears to be a radical ion and its parent spectrum suggests that it is the product of cleavage of the $\alpha \mathrm{C}-\mathrm{C}$ bond in $\mathrm{M}^{+}$with elimination of the elements of neutral pentene. This $\alpha$-cleavage process may occur by hydrogen atom transfer to the ionized nitrogen in a five-membered ring as shown in Scheme III. A similar process has been reported for $\mathrm{N}$-n-butylsuccinamide [38]. The methyl substituent in the ion $\mathrm{m} / z 311$ shows its presence by the fact that further fragmentation proceeds through ions $\mathrm{m} / z 241$ and 228 and ultimately leads to ions $m / z 158$ and 144 , respectively, rather than giving the lower homologue $m / z 130$.

The protonated trimer, $m / z 382$, is also an important precursor of the fragments at $m / z 228,158$, and 144 , as well as the fragment ion $m / z 242$, which is the
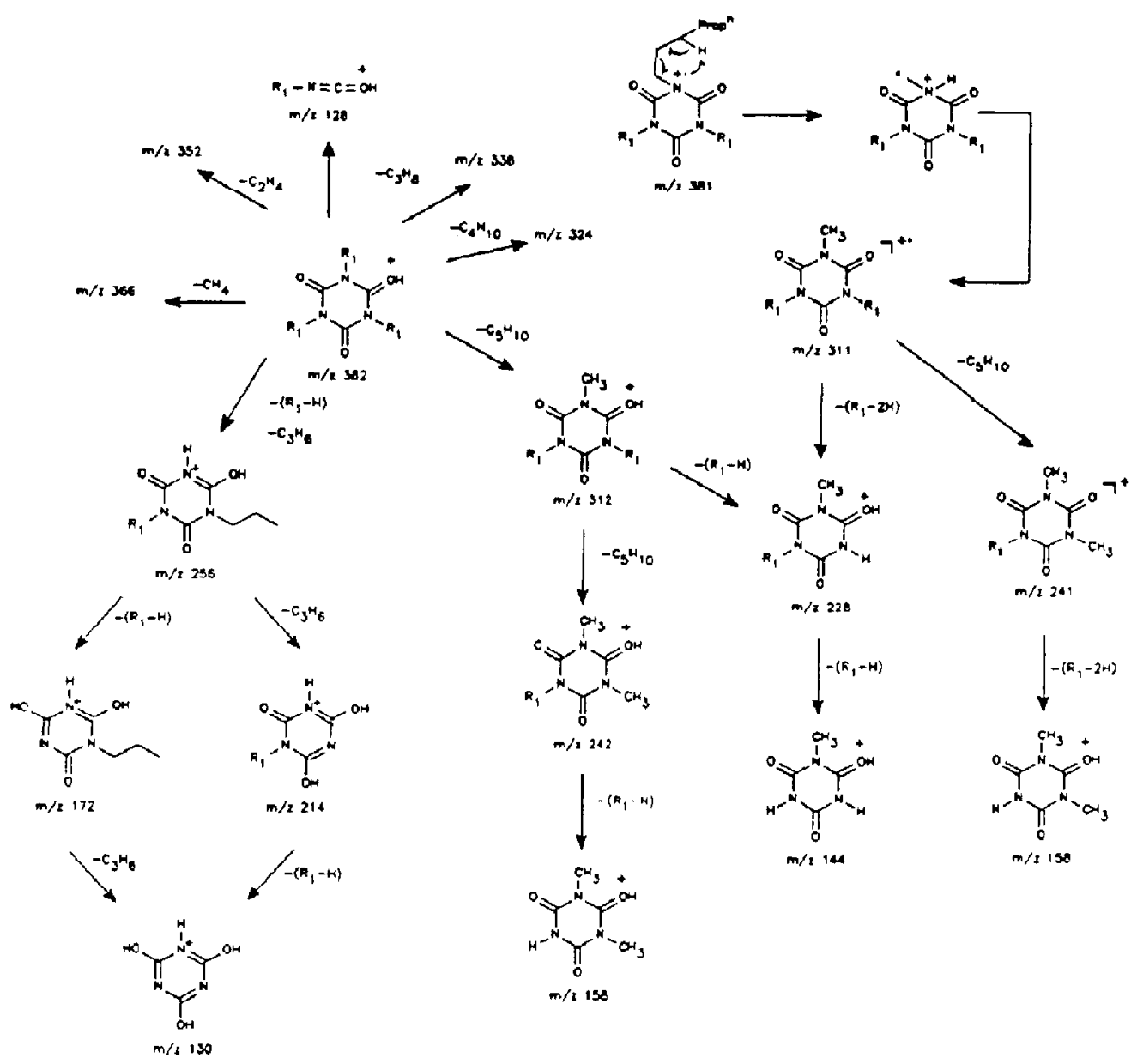<smiles>Cn1c(=O)[nH]c(=O)n(C)c1=O</smiles>

Scheme III 
base peak in the parent spectrum of $m / z$ 158. These findings indicate that $\alpha \mathrm{C}-\mathrm{C}$ bond cleavage also occurs in the protonated trimer (Scheme III).

The daughter spectra of the high-mass ions generated from the pyrolysate of Polymer-II do not show the $\alpha \mathrm{C}-\mathrm{C}$ bond cleavage intermediate products, although $m / z 270$ appears in the 70-eV DEI mass spectrum and in the parent spectra of $m / z 144$, as its major precursor. On the other hand, ion $m / z 298$ appears to be a $\beta C-C$ bond cleavage product. It is formed from ions $m / z 382$ and 508 , by processes that must involve loss of $\mathrm{C}_{6} \mathrm{H}_{12}$, and it fragments to $\mathrm{m} / z$ 172 and 130 , which suggests a cyanuric acid structure bearing an $R_{2}$ substituent and a propyl group. Another possible $\beta C-C$ cleavage product, ion $m / z 424$, is one of the parents of the ion $\mathrm{m} / z 127$ (Scheme IV).

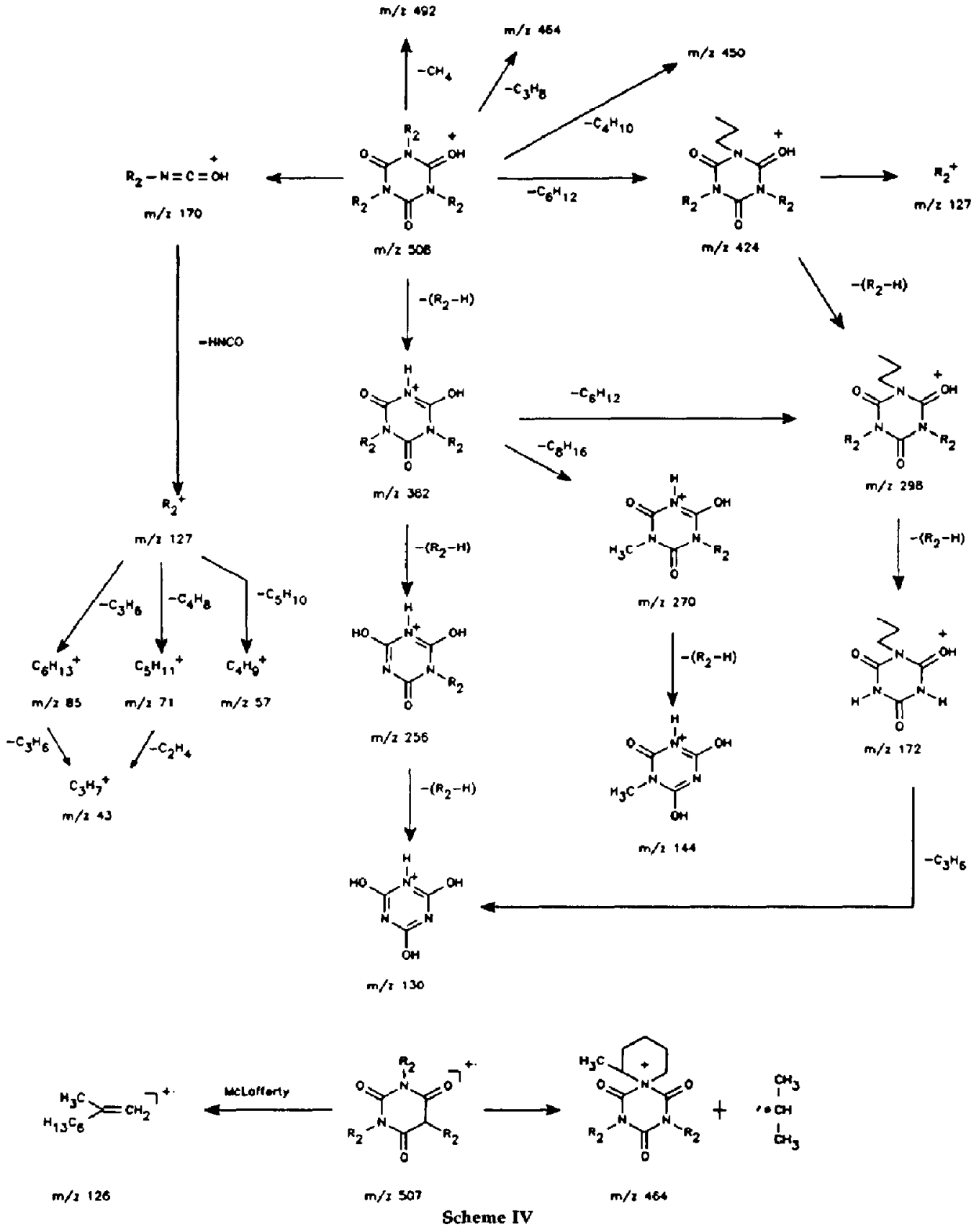


The near absence of the $\alpha$-cleavage analogue and the presence of $\beta$-cleavage products for Polymer-II are accounted for by the presence of the methyl substituent at the $\beta$ carbon in the $R_{2}$ chain. This substituent can stabilize the radical generated at this site upon a six-centered hydrogen transfer to the nitrogen that would occur in a $\beta$-cleavage process.

Radical stabilization at the $\beta$ carbon, within $\mathbf{R}_{2}$, may also explain the relatively abundant formation of the ionized alkene $(m / z 126)$ in the DEI mass spectra of Polymer-II. This ion can be generated from $\mathbf{M}^{+}$ $(m / z 507)$ by a McLafferty-type rearrangement [42] in which the stability of the radical at the $\beta$ carbon atom leads to retention of the charge by the alkene (Scheme IV).

A protonated cyanuric acid structure bearing a hexyl $\left(R_{1}\right)$ and a propyl group formed by a $\gamma C-C$ cleavage is attributed to the ion $\mathrm{m} / z 256$ (Scheme III). The protonated cyclic trimer, $m / z 382$, formed from Polymer-I is the major source of the ion $m / z 256$. The most important ions in the daughter spectrum of this fragment are $m / z 214,172$, and 130 (Table 2). This dissociation pattern indicates the presence of both propyl and hexyl substituents, loss of hexene yielding $m / z 172$, loss of propene yielding $m / z 214$, and loss of both groups as alkenes yielding $m / z 130$.

The DEI mass spectrum of Polymer-II (Table S-1) shows an ion at $m / z 464$ that may correspond to an ipso cyclic product due to $\epsilon C-C$ bond cleavage in the trimer radical cation $(m / z 507)$. This six-centered fragmentation process (Scheme IV) is probably favored by the stability of the isopropyl radical generated. The further fragments corresponding to sequential loss of the $R_{2}$ group as nonene from ion $m / z 464$ are also observed at $\mathrm{m} / \mathrm{z} 338$ and 212 .

Charge-remote fragmentations. Fragmentation formally remote from the charge site is expected in energetic even-electron ions, such as protonated amides, which bear long-chain alkyl substituents [39, 40]. The DEI and methane DCI mass spectra of Polymer-I display a series of low-abundance ions, $m / z$ 366, 352, 338, and 324, which may arise through charge-remote fragmentation (Table 1, Scheme III). These ions are formally due to alkane loss from the protonated trimer. The fact that they do not appear in any MS/MS spectra may be due to the low collision energy used in these experiments. We consider it unlikely that they are direct pyrolysis products because they should then appear in all the DCI spectra.

The charge-remote fragmentations evident in the $n$-hexyl case are also apparent in the nonyl case, i.e., Polymer-II. The position of branching of the $\mathrm{R}_{2}$ chain is discernible in these ions as seen by the fact that the alkane loss sequence is interrupted at $\mathrm{C}_{6}$; i.e., in the sequence $m / z 492,478,464$, and $450, m / z 478$ is absent (Table S-1, Scheme IV).

The above discussion demonstrates that carboncarbon bond cleavages within the alkyl chain make a contribution to the ion chemistry of the pyrolysate of Polymer-I and Polymer-II even though the major reactions are dominated by loss of the hexyl group in the form of hexene.

The protonated monomer. The ion $m / z 128$, which is very abundant in the methane DCI pyrolysis mass spectrum of Polymer-I, corresponds to protonated nhexylisocyanate, viz., to the protonated monomer. The fact that its abundance increases as the exothermicity of protonation increases suggests that it is, at least in part, the product of fragmentation of the protonated trimer (Scheme III). The parent spectrum of $m / z 128$ confirms this view. However, the presence of the isobutane adduct seen at $m / z 184$ in the isobutane $\mathrm{CI}$ mass spectrum provides evidence for direct generation of the monomer as a neutral product of pyrolysis. The daughter spectrum of $m / z 184(\mathrm{Ta}-$ ble 2) shows the isobutyl cation at $m / z 57$ and the protonated monomer at $m / z 128$ as major fragments. The formation of $m / z 128$ from $m / z 382$ requires that there exist a fragmentation pathway of the protonated trimer by a ring opening mechanism to yield the protonated monomer, an expected process.

The second major fragmentation process evident from the mass and MS/MS spectra of the protonated trimer $(m / z 508)$ generated from Polymer-II is the formation of the protonated monomer, $\mathrm{m} / z \mathrm{z}$ 170. The parent spectrum of this ion confirms that it arises, at least in part, as a dissociation product of the protonated trimer. Further fragmentation by HNCO loss to yield $R_{2}^{+}(m / z 127)$ and its fragments (Scheme IV) is apparent by a comparison of the daughter spectra of ions $m / z 170$ and 127 (Table S-2). The $\mathrm{NH}_{3}$ DCI mass spectrum shows the ammonia adducts $(m / z 525$ and 187) of the protonated trimer $(\mathrm{m} / z 508)$ and of the protonated monomer $(m / z 170)$. This result suggests a second route to the monomer, viz., that it is generated separately as a neutral molecule. The alternative, that the [monomer $\left.+\mathrm{NH}_{4}\right]^{+}$ion is a fragment of the [trimer $\left.+\mathrm{NH}_{4}\right]^{+}$ion was tested by recording the daughter spectrum of the latter (Table S-2). This spectrum shows abundant ions due to the normal alkene loss sequence without retention of the ammonia, $\mathrm{m} / \mathrm{z}$ 382,256 , and 130 . This indicates a weakly bound $\mathrm{NH}_{3}$, although $m / z 382$ was accompanied by a lowabundance ammonia adduct at $m / z 399$. Neither the monomer nor its ammonia adduct was observed, confirming the independent formation of the neutral monomer by pyrolysis.

The daughter spectrum of the ion $m / z 144$, generated by $\mathrm{NH}_{3} \mathrm{DCI}$, is distinctly different from that of $m / z 144$ when generated by DEI (Table S-2). The ion at $m / z 144$ in the $\mathrm{NH}_{3} \mathrm{DCI}$ mass spectrum is not the product of dissociation of $\left[\mathrm{M}+\mathrm{NH}_{4}\right]^{+}$, as shown by the daughter spectrum of the latter; however, it is generated from the ammonia adduct of the monomer, and it is therefore concluded that this ion corresponds to the protonated amine $\left[\mathrm{R}_{2} \mathrm{NH}_{2}+\mathrm{H}\right]^{+}$. The ammo- 


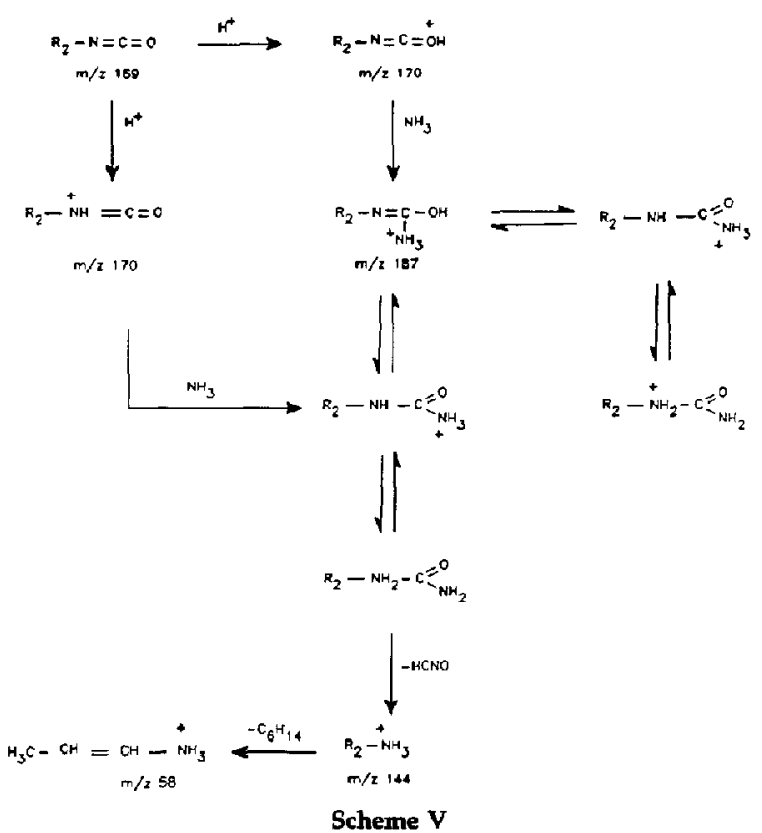

nia adduct of the monomer ( $\mathrm{m} / \mathrm{z} 187$ ) must he covalently bound, because its dissociation by HCNO loss to yield the protonated alkylamine $\mathrm{R}_{2} \mathrm{NH}_{3}^{+}$is suggested by the mass spectrum, confirmed by its daughter spectrum, and accounted for by the mechanism given in Scheme $V$. Note that there is ample precedent for covalent bond formation upon ammonia addition to multiple bonds, including the formation of Schiff bases in the gas phase [41].

Further evidence for the production of the neutral monomer during pyrolysis of Polymer-Il is found in the isobutane DCI mass spectrum. In addition to the protonated monomer, the monomer-isobutane adduct appears at $m / z 226$. The MS/MS daughter spectra of $m / z 226$ (Table S-2) show the butyl cation $(m / z 57)$ as the major fragment, along with the protonaled monomer, $m / z 170$.

The fragment ion $m / z 158$ in the DCI mass spectra of Polymer-III appears to be the protonated isocyanate monomer, and its parent spectrum shows the protonated trimer, $m / z 472$, and $m / z 284\left[\mathrm{MH}^{+}-114-58\right]$ as its major high-mass precursors. Therefore, a pathway in which the trimer fragments to yield the monomer is also operative for Polymer-III just as it is for Polymer-I and Polymer-ll. Even more of the protonated monomer $(m / z 158)$ is present in this case (Table S-3) than for the alkyl-substituted polymers, the ratio of protonated monomer to protonated trimer in the $\mathrm{CH}_{4}$ DCI mass spectrum being 0.4 for the $n$-hexyl, 9.0 for the nonyl, and 100 for the dioxolane derivative. As also noted for the nonyl polymer, the abundance of the protonated monomer increases relative to that of the protonated trimer as the exothermicity of protonation increases. This, together with direct evidence
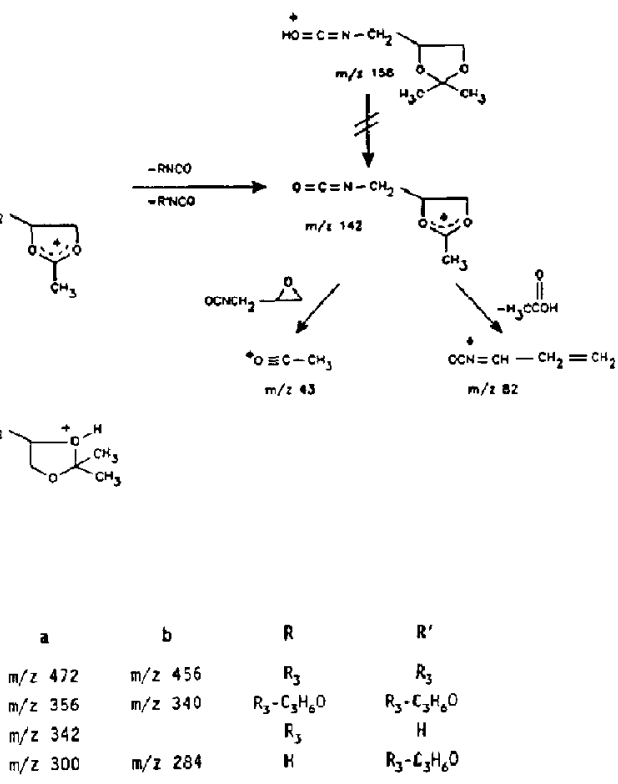

Scheme VI

from the parent and daughter spectra, establishes the interconnection of these two ions through fragmentation. However, as in the nonyl case, direct production of the neutral monomer by pyrolysis is also indicated here; the $\mathrm{NH}_{3} \mathrm{DCI}$ spectrum shows $\mathrm{NH}_{4}^{+}$adducts of the two suspected neutral pyrolysates, the trimer $(\mathrm{m} / \mathrm{z}$ 489) and the monomer $(m / z$ 175). Consistent with this, the major fragment of the protonated trimer, $m / z 414$, shows no ammonia adduct. Note that the isobutene adduct of the protonated monomer $(\mathrm{m} / \mathrm{z}$ 214) is also present in this polymer. These processes involving formation of the protonated monomer and its adducts are summarized in Scheme S-II.

Other Processes for Polymer-III. The parent spectrum of the abundant fragment ion $m / z 142$ (Table S-4) indicates the structure shown in Scheme VI. A retro Diels-Alder process is proposed involving loss of two RNCO groups, a process similar to that suggested for monomer formation from the protonated trimer (Scheme S-II). This structure is also consistent with its daughter spectrum. The fact that the protonated monomer $(\mathrm{m} / \mathrm{z}$ 158) does not lose methane to give the ion $m / z 142$, in analogy with methane loss from the protonated trimer, suggests that its charge is located on the isocyanate rather than the dioxolane ring. This is consistent with the expected increase in proton affinity of the isocyanate over the cyanuric acid group.

The ion $m / z$ 114, which appears in the DEI mass spectra, is probably $\left[\mathrm{R}_{3}-\mathrm{H}\right]^{+}$. Its formation in relatively good abundance may be explained, in analogy with the formation of the ion $\mathrm{m} / \mathrm{z} 126$ from PolymerII, by the stability of the radical that is formed at the $\beta$ 


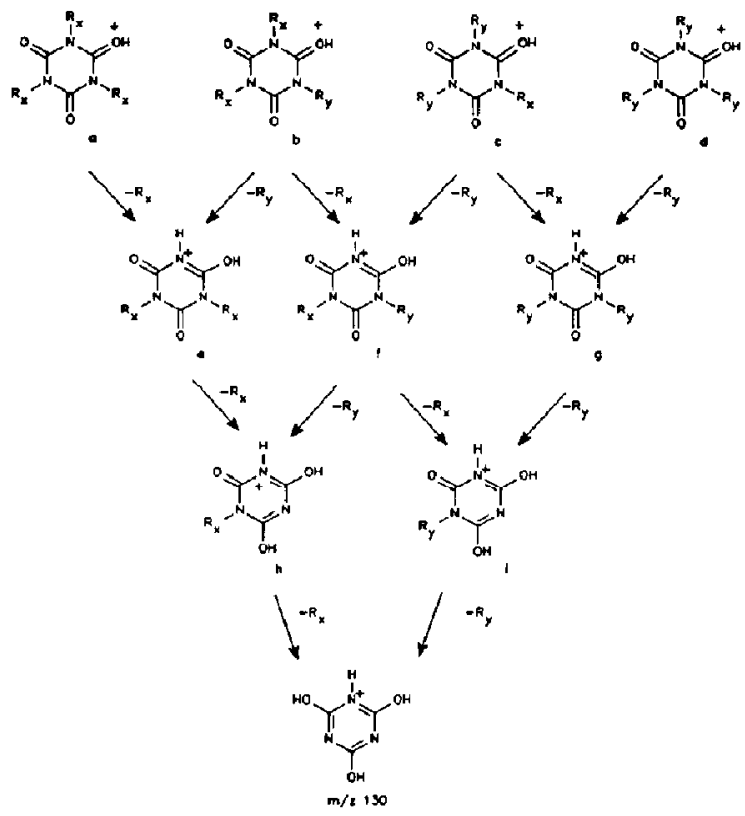

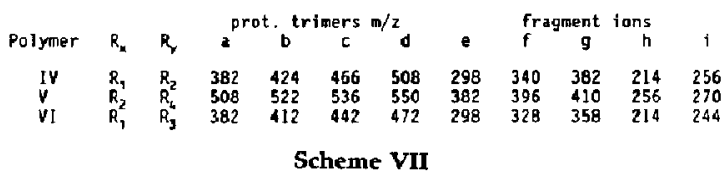

carbon of the $R_{3}$ group when fragmentation occurs through a McLafferty-type rearrangement with retention of the charge by the alkene [42]. From the above discussion it is clear that post-ionization fragmentation of thermally decomposed Polymer-III is quite different from the furst two polymers because of the presence of the dioxolane substituent.

\section{Copolymers}

Major pyrolysis products and fragmentation pathways. Copolymers having two different types of substituents might produce four different trimers upon pyrolysis, each of which can lose their alkyl groups as alkenes to give protonated cyanuric acid, $m / z 130$, through the fragmentation pathway shown in Scheme VII ( $R_{4}=3,7$-dimethyloctyl group).

Pyrolysis mass spectra of Polymer-IV and Polymer$V$ display the four protonated trimers at $m / z 508$, 466,424 , and 382 (Table 3), and at $m / z 550,536,522$, and 508 (Table $5-5$ ), respectively. The parent spectra of $m / z 130$ generated from these copolymers show all four trimers and the expected alkene loss fragments (Figure 4). The isobaric nature of ion $m / z 382$ in Polymer-IV (Scheme VII) is clearly seen by the reaction intermediate spectrum (Figure 5a), which shows the two competitive routes from ion $\mathrm{m} / \mathrm{z} 382$ to protonated cyanuric acid: loss of two $\mathrm{C}_{9} \mathrm{H}_{18}$ or loss of three $\mathrm{C}_{6} \mathrm{H}_{12}$ molecules.
The alkene loss processes for the asymmetrical protonated trimer, $m / z$ 424, generated from Polymer-IV are revealed with startling clarity in the reaction intermediate spectrum (Figure 5b). This mode of scanning removes contributions from all other processes. It is of interest that one possible process, the loss of two molecules of hexene in sequence (ion $m / z 256$ ), is observed in very low abundance in this spectrum. The preferential loss of the larger alkene, i.e., nonene over hexene, can be simply accounted for by the fact that the hydrogen bound to a tertiary carbon in the nonyl group can be transferred more readily than that bonded to a secondary carbon in the n-hexyl group through the mechanism proposed in Scheme I. The reaction intermediate spectrum for the other asymmetrical trimer, $m / z 466$ (Figure 5c), again shows favored loss of the larger alkene. In this spectrum, only the large alkene loss fragment ions occur at $m / z$ 340 and 214 (Scheme VII). This is also confirmed in the daughter spectrum of ion $m / z 340$ (Scheme VII, Table 4), which shows a preference of more than 40:1 for loss of the larger alkene ( $m / z$ 214) over the smaller $(m / z 256)$. The formation of the same protonated trimer of $m / z 508$ from this copolymer (Polymer-IV) and from Polymer-II is revealed by the similarity of their reaction intermediate spectra (shown for Polymer-IV in Figure 5d), which display the two expected intermediates (Scheme VII).

The reaction intermediate spectra for the four protonated trimers generated from Polymer- $\mathrm{V}$ reveal the fragmentation routes to protonated cyanuric acid as shown in Figure 6. As expected, the two symmetrical trimers, $m / z 508$ and 550 (Figure 6a and $d$, respectively), show just the two alkene loss intermediate ions. The asymmetrical nonyl-didecyl trimer, $m / z 536$, shows three intermediate ions, $m / z$ 410, 396, and 270 (Figure 6c). The competitive losses of nonene and decene yield the furst two ions. Remarkably, the sequence $m / z 536\left([\mathrm{M}+\mathrm{H}]^{+}\right) \rightarrow 396 \rightarrow 256 \rightarrow 130$, in which the alkenes lost are, in order, decene, decene, and nonene, is not observed. The fact that the very similar sequences decene, nonene, decene $(536 \rightarrow 396$ $\rightarrow 270 \rightarrow 130)$ and nonene, decene, decene $(536 \rightarrow 410$ $\rightarrow 270 \rightarrow 130$ ) are observed can nevertheless be readily explained by the fact that nonene but not decene loss can occur by transfer of a hydrogen bound to a tertiary carbon, through the mechanism shown in Scheme I. Note that the missing ion $m / z 256$ does occur in the mass spectrum (Table S-5), and its MS/MS daughter and parent spectra (Table S-6) show that this ion does fragment to yield $m / z \quad 130$ and that it does arise from $m / z 536$. Corresponding selectivity is observed in the reaction intermediate spectrum of the other asymmetrical trimer, $m / z 522$ (Figure 6b).

The protonated tri( $n$-hexyl) trimer $(m / z 382)$ is the only trimer observed in both the $70-\mathrm{eV}$ and the $15-\mathrm{eV}$ DEI pyrolysis mass spectra of Polymer-VI (Table S-7). The protonated singly and doubly $R_{3}$ (dioxolane group)-substituted trimers ( $m / z 442$ and 412) are ob- 
Table 3. Direct pyrolysis mass spectra of Polymer-IV, obtained with different ionization methods ${ }^{\mathbf{a}}$

\begin{tabular}{|c|c|c|c|c|c|}
\hline \multirow[b]{2}{*}{$m / z$} & \multicolumn{2}{|c|}{ DEl methods } & \multicolumn{3}{|c|}{ DCl methods } \\
\hline & $70 \mathrm{eV}$ & $15 \mathrm{eV}$ & $\overline{\mathrm{NH}_{3}}$ & $i$-butane & $\mathrm{CH}_{4}$ \\
\hline 525 & - & - & 8 & - & - \\
\hline 508 & 1 & 2 & - & 7 & 4 \\
\hline 483 & 89 & - & 45 & - & - \\
\hline 466 & 12 & 11 & 28 & 47 & 34 \\
\hline 452 & - & - & - & - & 7 \\
\hline 441 & - & - & 100 & - & - \\
\hline 424 & 30 & 23 & 60 & 100 & 100 \\
\hline 408 & - & 1 & - & - & 9 \\
\hline 399 & - & - & 65 & - & - \\
\hline 382 & 28 & 20 & 40 & 71 & 71 \\
\hline 381 & 8 & 7 & - & - & - \\
\hline 366 & 1 & 2 & - & - & 4 \\
\hline 352 & 2 & 2 & - & - & 1 \\
\hline 340 & 48 & 66 & - & 1 & 4 \\
\hline 323 & 3 & 3 & - & - & - \\
\hline 311 & 2 & 2 & - & - & - \\
\hline 298 & 100 & 100 & 2 & 2 & 5 \\
\hline 281 & 3 & 2 & - & - & - \\
\hline 254 & 1 & - & - & - & - \\
\hline 256 & 4 & - & - & - & - \\
\hline 242 & 2 & - & - & - & - \\
\hline 228 & 8 & - & - & - & - \\
\hline 226 & - & - & - & 8 & - \\
\hline 214 & 13 & - & - & - & - \\
\hline 184 & - & - & - & 5 & - \\
\hline 183 & 2 & - & - & - & - \\
\hline 170 & 4 & - & - & 3 & 30 \\
\hline 154 & 2 & - & - & - & 2 \\
\hline 144 & 5 & - & 1 & - & - \\
\hline 130 & 16 & - & 2 & - & - \\
\hline 128 & - & - & - & 6 & 61 \\
\hline 126 & 11 & 3 & - & - & 20 \\
\hline 113 & 11 & $\mathbf{3}$ & - & 13 & 3 \\
\hline
\end{tabular}

Isotopic peaks and ions less than $1 \%$ in relative abundance are not reported.

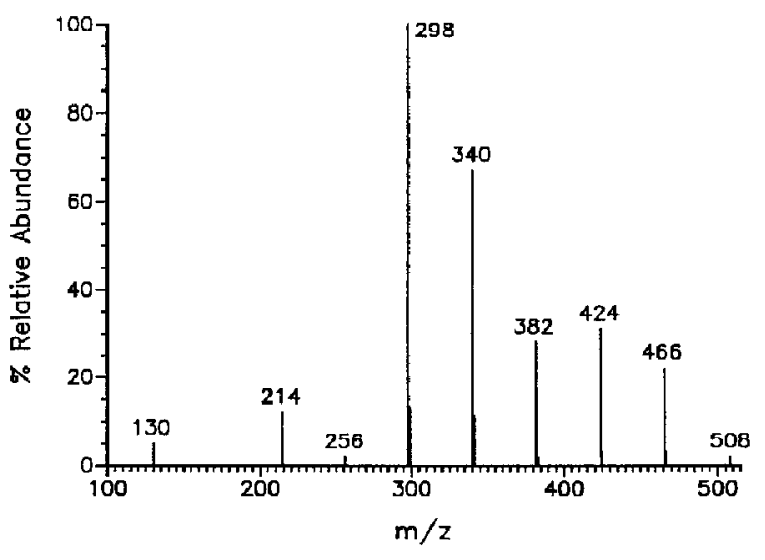

A

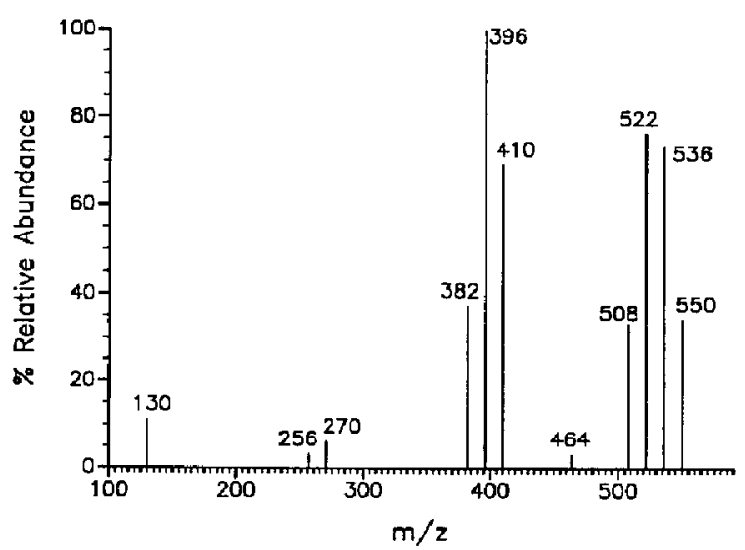

B

Figure 4. MS/MS parent spectrum of $m / z 130$ from Polymer-IV and Polymer- $V$. 


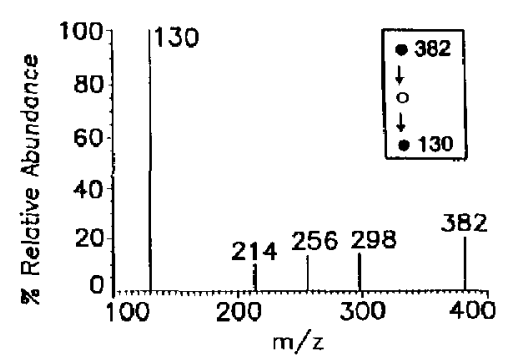

$\mathbf{A}$

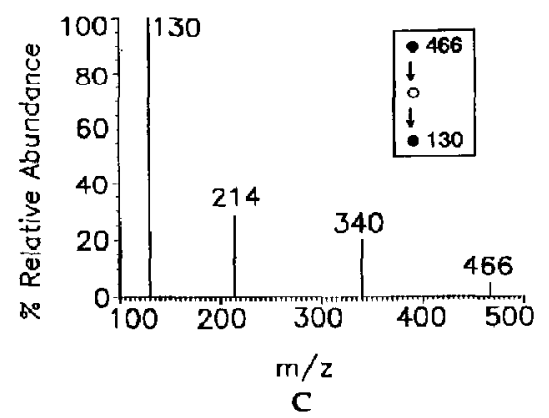

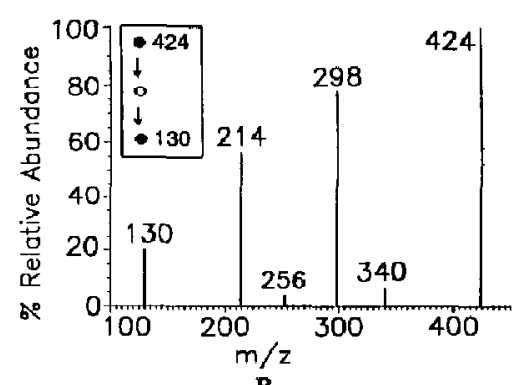

B

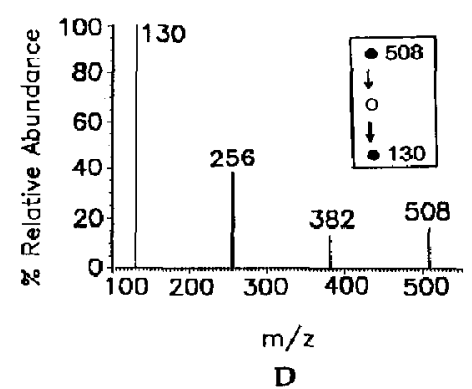

Figure 5. $M S^{3}$ reaction internediate spectra of the protonated trimers at (a) $\mathrm{m} / \mathrm{z} 382$, (b) $\mathrm{m} / \mathrm{z}$ 424, (c) $m / z$ 466, and (d) $m / z 508$, from Polymer-IV. served only in low abundance in the 15-eV DEI spectrum, and the protonated tri- $\mathrm{R}_{3}$-substituted trimer $(m / z 472)$ is not observed in any DEI spectra. This is not surprising, because the protonated trimer expected for Polymer-III was not observed in its DEI spectra either. The ions at $m / z 456,426$, and 396, which are formally either the methyl radical loss products from the molecular ion or the products of methane loss from the protonated trimers $m / z 472,442$, and 412, respectively, are observed in both DEI spectra. However, formation during pyrolysis of all four intact protonated trimers and two different monomers $(\mathrm{m} / \mathrm{z}$ 128 and 158) is evident from the methane and isobutane DCI spectra (Table S-7), which display these ions at high abundance. Daughter spectra of each of these ions (Table S-8) are consistent with the fact that they

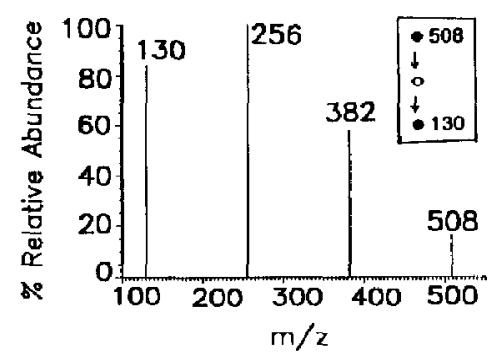

A

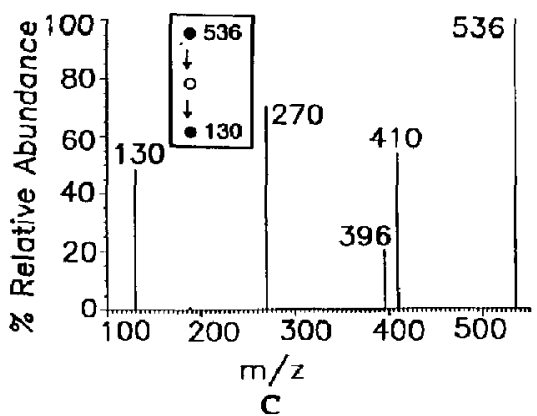

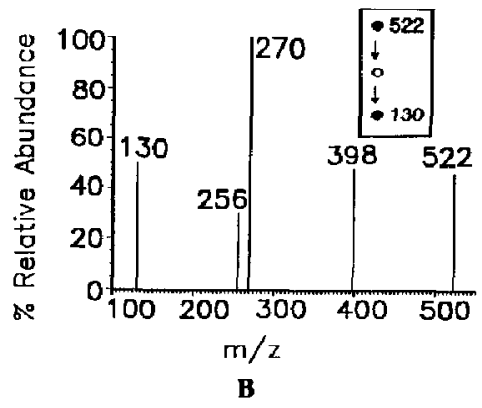

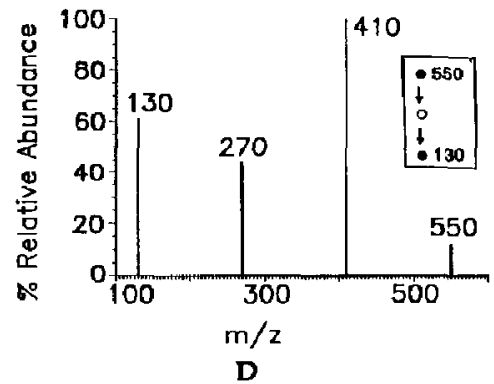

Figure 6. $M S^{3}$ reaction intermediate spectra of the protonated trimers at (a) $m / z 508$, (b) $m / z$ 522, (c) $m / z 536$, and (d) $m / z 550$, from Polymer-V. 
Table 4. MS/MS spectra of the major ions of Polymer-IV

\begin{tabular}{|c|c|c|}
\hline Selected ion $m / z$ & $\begin{array}{l}\text { Daughter ions } m / z \\
\text { (\% relatlve abundance) }\end{array}$ & $\begin{array}{l}\text { Parent ions } m / z \\
\text { (\% relative abundance) }\end{array}$ \\
\hline$\overline{525^{b}}$ & $508(100), 382(91), 256(16), 130(13)$ & None observed \\
\hline 508 & $\begin{array}{l}464(1), 382(50), 256(72), 170(18) \\
144(6), 130(100), 85(40), 71(15)\end{array}$ & $525(100)^{\mathrm{D}}$ \\
\hline $483^{b}$ & $466(94), 340(100), 214(67), 130(81)$ & None observed \\
\hline 466 & $\begin{array}{l}340(75), 214(100), 170(8), 130(85) \\
85(30), 71(22)\end{array}$ & $483(100)^{\mathrm{b}}$ \\
\hline $441^{b}$ & $\begin{array}{l}424(61), 340(6), 315(1), 298(100) \\
214(29), 130(4)\end{array}$ & None observed \\
\hline 424 & $\begin{array}{c}340(15), 298(100), 256(2), 214(66) \\
170(3), 130(88), 85(32), 71(12)\end{array}$ & $441(100)^{b}$ \\
\hline $399^{b}$ & $\begin{array}{l}382(100), 315(1), 298(95), 214(46) \\
130(13)\end{array}$ & None observed \\
\hline 382 & $\begin{array}{l}298(46), 266(6), 214(42), 130(100) \\
128(23), 87(3), 85(81), 71(10) \\
57(5), 43(7)\end{array}$ & $\begin{array}{l}466(19), 508(100), \\
399(100), b 25(1)^{b}\end{array}$ \\
\hline 340 & $\begin{array}{l}256(1), 214(43), 130(100), 85(19) \\
71(13), 57(7), 43(3)\end{array}$ & $466(100), 424(8)$ \\
\hline 298 & $\begin{array}{c}214(20), 130(100), 87(8), 85(6) \\
59(1), 57(7), 43(14)\end{array}$ & $\begin{array}{l}424(100), 408(2) \\
382(37)\end{array}$ \\
\hline 256 & $\begin{array}{l}214(4), 172(5), 130(100), 87(19) \\
85(6), 71(17), 70(2), 57(10), 43(37)\end{array}$ & $\begin{array}{l}508(39), 492(22) \\
479(5), 466(56) \\
424(40), 382(100) \\
340(72)\end{array}$ \\
\hline 228 & $\begin{array}{l}144(100), 101(4), 87(11), 70(2) \\
57(42), 43(32)\end{array}$ & $\begin{array}{l}382(100), 366(10) \\
\quad 311(85)\end{array}$ \\
\hline 226 & $\begin{array}{c}170(7), 85(12), 71(25), 57(100) \\
43(100), 41(4), 29(2)\end{array}$ & None observed \\
\hline 214 & $\begin{array}{c}130(100), 87(38), 85(5), 70(5) \\
59(3), 57(14), 43(98)\end{array}$ & $\begin{array}{l}466(40), 424(100) \\
382(30), 340(39) \\
298(41)\end{array}$ \\
\hline 184 & $\begin{array}{c}142(1), 128(4), 85(31), 57(100) \\
43(61), 41(9), 29(3), 27(2)\end{array}$ & None observed \\
\hline 170 & $\begin{array}{c}127(11), 87(15), 85(9), 71(75) \\
58(73), 55(98), 43(100)\end{array}$ & $\begin{array}{c}508(30), 466(27) \\
442(3), 424(100) \\
382(19), 340(3) \\
338(22), 310(5)\end{array}$ \\
\hline $144^{\circ}$ & $87(10), 70(5), 59(92), 57(3), 43(100)$ & $\begin{array}{l}508(6), 466(4), 424(5), \\
396(53), 382(9) \\
354(40), 312(100) \\
298(6), 282(11) \\
270(19), 228(98), \\
214(8), 186(16)\end{array}$ \\
\hline $130^{c}$ & $87(4), 70(6), 43(100)$ & $\begin{array}{l}508(3), 466(20) \\
424(31), 382(30) \\
340(67), 298(100) \\
256(2), 214(6)\end{array}$ \\
\hline $126^{c}$ & & $\begin{array}{l}466(35), 424(20) \\
382(55), 324(100) \\
170(59)\end{array}$ \\
\hline
\end{tabular}

represent the four intact protonated trimers, where loss of acetone produces the more abundant fragment ions from the dioxolane-substituted protonated trimers, $m / z$ 414, 384, and 354, respectively. The alkene elimination sequence ending at $\mathrm{m} / \mathrm{z} \quad 130$ (Scheme VII) is also observed. Daughter spectra of ions $m / z 382,298,256,214,158,144$, and 130 are similar to those observed for the ions having the same mass-to-charge ratio from Polymer-I (Table 2). Therefore, these ions have the structures described in Schemes I and III. The ion $m / z 101$ observed for Polymer-III (Scheme II) is also present in high relative abundance in the DEI mass spectrum of this copolymer. 
Carbon-Carbon bond cleavages. The occurrence of these processes is observed in the mass and MS/MS spectra of Polymer-IV and Polymer-V. The 70-eV DEI spectrum for Polymer-IV displays three expected $\alpha$-cleavage ions, $m / z 311,228$, and 144 . The parent spectrum of ion $m / z 144$, the $N$-methyl homologue of $m / z$ 130, displays all four protonated trimers, along with all the N-methylated precursors, $m / z$ 396, 354, 312,270 , and 228 . The $\alpha$-cleavage is clearly shown for Polymer-V by the presence in the mass and MS/MS spectra (Tables S-5 and S-6) of the N-methyl cyclic terminal ions, $m / z 144$ and 158 , and their precursors, ions $m / z$ 270, 284, 298, 396, 410, and 424 (Scheme VIII): The preferential $\alpha$-cleavage in $R_{4}$ over $R_{2}$ is expected from the fact that $R_{2}$ has a methyl group at the $\beta$-carbon, as discussed for Polymer-II, and is evident from the fact that $\mathrm{m} / z 424,410$, and 396 are not displayed in the daughter spectra of the protonated trimers $m / z 536,522$, and 508 , respectively. These fragmentations would involve $\alpha$-cleavage in $R_{2}$ and loss of pentene. This process is observed only to a small extent and is exemplified by the presence of the protonated tri- $\mathrm{R}_{2}$-substituted trimer $(\mathrm{m} / z$ 508) in the parent spectrum of $m / z 144$.

It is interesting to note that the $R_{2} \epsilon$-cleavage products are observed in the DEI mass spectra of Polymer-V ( $m / z \quad 492,478$, and 464), but the corresponding $\mathbf{R}_{4}$ product ( $m / z 506$ ) is missing. This process for $R_{4}$ would involve loss of the same stable isopropyl radical as for $R_{2}$ but would occur via a seven- rather than a six-membered intermediate.

That ions $m / z$ 270, 396, and 410 from Polymer-V each consist of two isobars, one originating by $\alpha$ $\mathrm{C}-\mathrm{C}$ cleavage and the other by the alkene loss sequence (Scheme VII), is confirmed by their daughter spectra, which display the two expected cyclic termi-

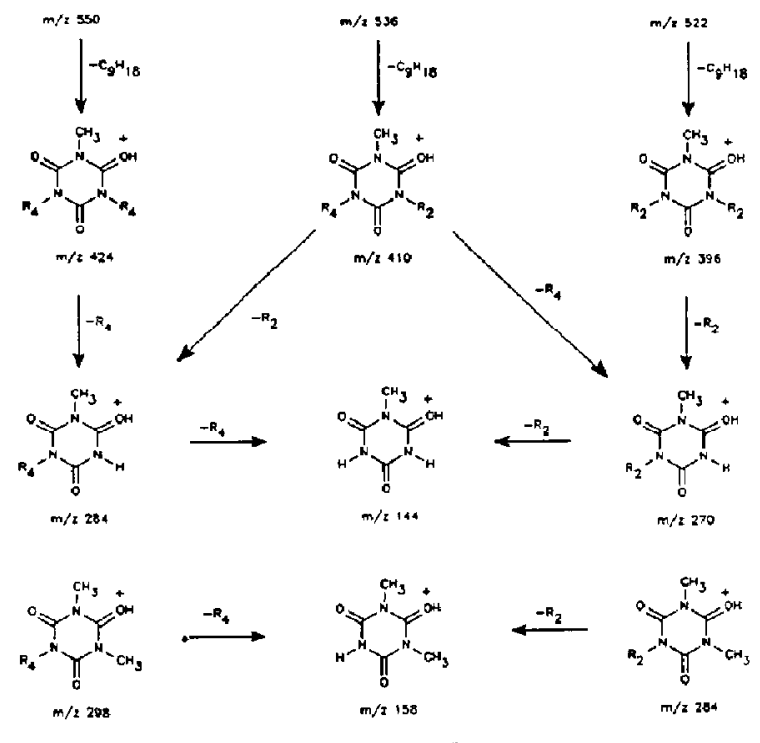

Scheme VIII nal ions, $m / z 144$ and 130 . In the same way, the occurrence of two isobaric forms of the ion $m / z 284$, one having one methyl substituent and the other having two, is evident in its daughter spectrum, which displays both the mono- $(m / z 144)$ and the dimethylated ( $m / z 158$ ) cyclic ions. Furthermore, the occurrence of two isobaric forms of the ion $m / z 298$, one due to the double $\alpha \mathrm{C}-\mathrm{C}$ cleavage product (Scheme VIII) and the other to the $\beta \mathrm{C}-\mathrm{C}$ cleavage product from $m / z 508$ (Scheme IV), is evident in its MS/MS daughter spectrum. The daughter spectrum of this ion displays both the cyclic dimethylated ion $m / z 158$ and the daughter ions expected from the $\beta$-cleavage, ions $m / z 172$ and 130.

Charge-remote fragmentation. This process is seen to a very small extent in the DEI mass spectra of PolymerIV and Polymer-V. Polymer-IV displays only ion $m / z$ 408, which can be formed by this process. Ions $m / z$ 492, 478, and 464 for Polymer- $V$, which have been assigned as $\epsilon$-cleavage products, can also be generated from the protonated trimer by charge-remote fragmentation.

Protonated monomers. The ions $m / z 184$ and 226 in the isobutane spectrum for Polymer-IV are the isobutane adducts of the monomers discussed in connection with Polymer-I and Polymer-II, respectively. The ion $m / z 170$ has the same daughter spectrum as that observed for the ion of the same mass generated from Polymer-II (Table S-2), which indicates that $\mathrm{m} / z 170$ is the protonated monomer of 2,6-dimethylheptylisocyanate.

The MS/MS data for $m / z 184\left(\mathrm{R}_{4} \mathrm{NCOH}^{+}\right)$and $m / z 170\left(\mathrm{R}_{2} \mathrm{NCOH}^{+}\right)$observed in the $\mathrm{DCI}$ mass spectra of Polymer-V (Table S-5) suggest that they are the protonated monomers. Their parent spectra display the intact trimers as precursors. Formation of monomers during pyrolysis is also evident from the generation of isobutene adducts of the monomers, observed at $\mathrm{m} / \mathrm{z} 226$ and 240 , during isobutane DCI (Table S-5).

The isobutene adducts of the monomers discussed earlier in the cases of Polymer-I and Polymer-III are also present for Polymer-VI at $m / z 184$ and 214 following isobutane DCI (Table S-7). The ion $m / z 214$ observed during 70-eV DEI is isobaric with the ion $\mathrm{m} / \mathrm{z} 214$ observed during isobutane $\mathrm{DCl}$. which is clear from the MS/MS spectra shown in Table S-8.

Other processes. As seen in other cases, the ammonia DCI mass spectrum of Polymer-VI (Table 5-7) also shows direct evidence for the generation of the neutral trimer molecules in the form of the ammonia adducts, $m / z 489(472+17), m / z \quad 459(442+17)$. $m / z 429(412+17)$, and $m / z 399(382+17)$. The ammonia adduct of one monomer is also observed at 
<smiles>[R5]n1c(=O)n([2H])c(=O)n(C23COC(C)(C)OC2C3C)c1=O</smiles>

$m / 2426$

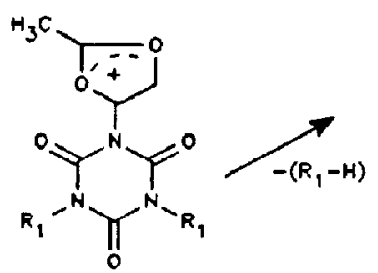

$\mathrm{m} / 2396$

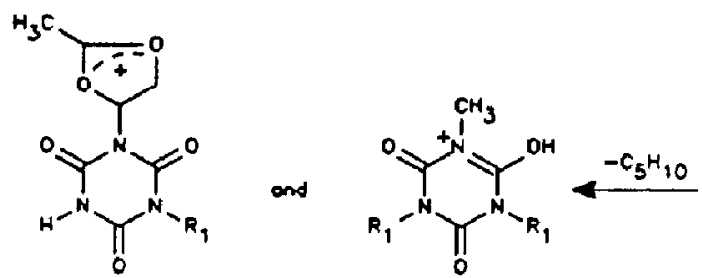

$\mathrm{m} / 2312$<smiles>O=c1n([12F])c(=[18O])n([18F])c(=O)n1P</smiles>

$m / 2382$

Scheme IX

$m / z 175(158+17)$, as well as ammonia adducts of the fragment ions $m / z 426(m / z 443)$ and $m / z 396$ ( $m / z$ 413). These two latter adducts appear to be formed by loss of 46 (from the trimers $\mathrm{m} / z 472$ and 442 , respectively). This reaction was not encountered in the homopolymers and is therefore ascribed to combined loss of 16 and $30 \mathrm{u}$ due to fragmentation involving participation of both the $R_{3}$ and $R_{1}$ chains. The ion $m / z 473$, which is the ammonia adduct of $m / z 456$, was also observed although in low abundance. These low-abundance ammonia adducts of fragment ions are significant, since they may indicate a covalently bound ammonium adduct of the trimer, although they could also be formed from the fragments themselves in the ion source. This result also contrasts with that observed for the homodioxolane polymer (Polymer-III) where fragmentation of the ammonia trimer adduct led overwhelmingly to loss of ammonia.

The MS/MS daughter spectra of $m / z 312$ for Polymer-VI (Table S-8) indicate the existence of two isobars: the first produced from $m / z 426$ by the loss of nonene and from $\mathrm{m} / \mathrm{z} 396$ by the loss of hexene, and the second derived from the protonated $n$-hexylisocyanate trimer $(m / z 382)$ by $\beta$-cleavage, as shown in Scheme IX. The MS/MS data on the ion $m / z 270$ (Table $\mathrm{S}-8$ ) is best interpreted by assigning three different cyclic structures for this ion formed by the fragmentation pathways shown in Scheme $X$.

The parent spectrum of $m / z 354$ shows only $m / z$ 412 as its precursor, and its daughter spectrum shows $m / z 298$ as the most abundant fragment, as well as other fragments at $m / z 270,214,186$, and 130 . It is therefore evident from the MS/MS data that this ion $(m / z 354)$ is formed from $m / z 412$ by loss of acetone and that it fragments to $m / z 130$ by the routes suggested in Scheme XI.

\section{Distribution of Monomers}

It is of interest to test the capabilities of mass spectrometry to determine the distribution of monomers in a copolymer. In the case of the polyalkylisocyanates, NMR methods are available although they require relatively large amounts of sample [36, 37]. In the case of a random distribution of monomers, the probabilities of forming different trimer ions can be estimated by simple statistics, considering only the monomer ratio used during synthesis of the copolymer. The theoretical distribution can be calculated by the general formula:

i.e.,

$$
P={ }^{m} C_{a}^{n} C_{b} / /^{(m+n)} C_{(a+b)}
$$

$$
\begin{aligned}
P- & {[\{m ! / a !(m-a) !\}\{n ! / b !(n-b) !\}] / } \\
& {[(m+n) ! /(a+b) !(m+n-a-b) !] }
\end{aligned}
$$

where

$P=$ probability of observing a particular trimer,

$m=$ proportion of the first monomer.

$n=$ proportion of the second monomer,

$a=$ number of first monomer groups in the trimer, and

$b=$ number of second monomer groups in the trimer.

The measured distribution of trimers was simply calculated by using the formula $x_{i} / \Sigma\left(x_{i}\right)$, where $x_{i}=$ percent relative abundance of the individual trimer ions. Because the theoretical calculation shown above is based on a random distribution of monomers, 
<smiles>[B]n1c(=O)n(S)c(=O)n(CC23COC(C2)O3)c1=O</smiles>

$m / 2455$<smiles>[R]Nn1c(=O)n([R])c(=O)n([R])c1=O</smiles>

$$
\frac{-C_{3} H_{6} O}{-\left(R_{1}-H\right)}
$$

$\mathrm{m} / 2412$<smiles>CCCn1c(=O)[nH]c(=O)n(CC23CO[C](C2)C(C)O3)c1=O</smiles>

$\mathrm{m} / 2270$<smiles>CC1O[C@@H]2CO[C@@H]1C2Cn1c(=O)[nH]c(=O)n(CC=O)c1=O</smiles>

$\mathrm{m} / 2270$<smiles>[R]n1c(=O)[nH]c(=O)n(CC2CO2)c1=O</smiles>

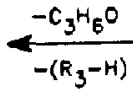

$\mathrm{m} / 2270$<smiles>[R7]n1c(=O)[nH]c(=O)n(CC23CO[C@@](C)(O2)C3(C)C)c1=O</smiles>

$\mathrm{m} / 2312$

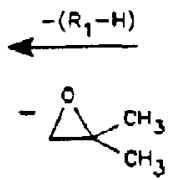<smiles>[R3]n1c(=O)n([R])c(=O)n(CC23COC(C)(O2)C3C)c1=O</smiles><smiles>[R]n1c(=O)n([R])c(=O)n([R3])c1=O</smiles>

$m / 2442$

Scheme $X$

agreement between the experimental data and the theoretical data would imply a random distribution; otherwise the distribution must be nonrandom.

To use the above approach one must be confident that the ion abundances of the protonated trimers reflect the relative proportions in which the neutral trimers are generated. There are three potential sources of error: (1) the relative rates of protonation, (2) the occurrence of processes in the neutral or ion that might lead to scrambling of the substituents or other distortions of the distribution, and (3) differential rates of fragmentation, which would have the same effect. The rates of protonation are taken to be equal, given the similarities expected for proton affinities of the various substituted cyanuric acids. To test the second point, pyrolysis mass spectra were recorded on mixtures of homopolymers under both DEI and DCI conditions. Several different mixtures in different proportions were examined and the results, collected in Table S-9, show that no trimer with mixed substituents was formed. This eliminates the occurrence of substituent interchange in the neutral or in the ionic state. That the third requirement is not completely satisfied is evident from the results presented so far. Correction of the mass spectra for the effects of different rates of fragmentation could be done in principle by summing all ions derived from the particular protonated trimer. This is difficult because the different trimers in a mixture give many common fragments, including isobaric ions of the same nominal mass. This led to the adoption of a method in which each substituent was assigned a 


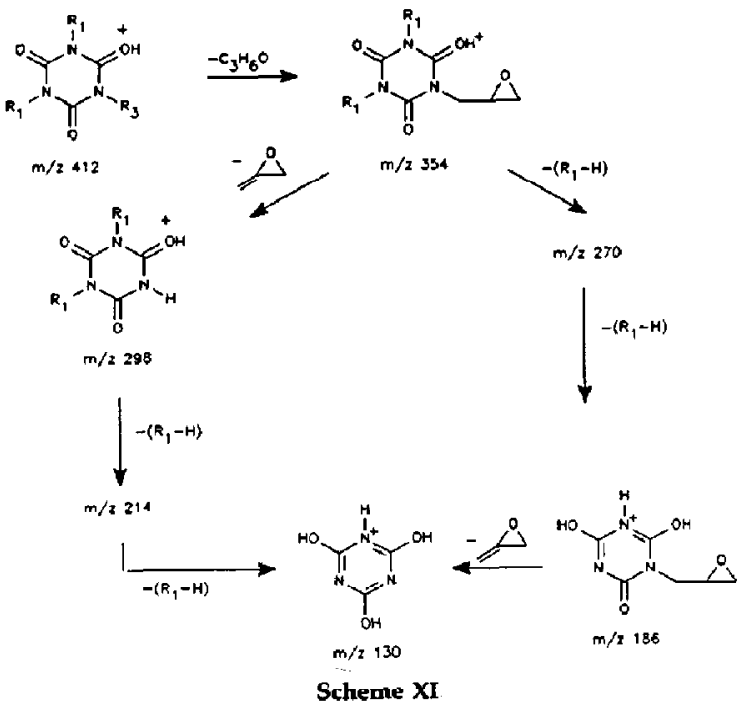

dissociation efficiency, viz., the substituent dissociation efficiency, $R_{x} \equiv \mathrm{MH}^{+} / \Sigma \mathrm{F}_{\mathrm{i}}^{+}$, which was evaluated by measuring the extent of dissociation of the corresponding protonated homotrimer under standard MS/MS conditions. A dissociation efficiency for each protonated trimer was then estimated by arithmetically averaging the substituent values. The dissociation efficiency values of the different trimers are included in Table 5 as correction factors. Correction for dissociation of the ionized copolymers was performed by multiplying the relative abundance of each trimer by the reciprocal of the correction factor. The corrected probabilities of formation of each of the trimers are reported in Table 5, together with the uncorrected values for each copolymer. The theoretical values, which assume a random distribution, are given under the heading "Calculated probability." Because of extensive dissociation at high energy, the corrected protonated trimer abundance was least reliable with the 70-eV DEI data; therefore only the $15-\mathrm{eV}$ data are recorded.

The 15-eV DEI data for Polymer-IV and Polymer-V agree well with the theoretical values expected for a random distribution of the monomers. This is in agreement with NMR results, which are not readily applied to copolymers in which the alkyl side chains are homologous [36, 37]. Variations could arise due to the implicit assumption that the interactions between the substituents have negligible kinetic effects, both in the formation of the neutral trimers from the polymer and in the dissociation of the ion. In Polymer-IV one would expect isobaric interference for the trimer $\mathrm{m} / \mathrm{z}$ 382 (discussed earlier) to give an erroneous result in the calculation of the monomer distribution. As we see in Table 5, the experimental results agree well with the calculated results, which proves that the isobaric interference for $m / z \quad 382$ is negligible under low-energy ionization conditions and that the majority of the $m / z 382$ ions are the protonated tri $(n$ hexyl)isocyanate trimer. Another reason for the negligible isobaric effect is that the copolymer contains approximately two $n$-hexyl groups for every 2,6 -dimethylheptyl group, and the rate of fragmentation of the trimers $m / z 508 \rightarrow 382$ and $m / z \quad 382 \rightarrow 298$ is much slower in the copolymer than in the homopolymers (evident from the abundance ratio of $382 / 508$ at 15-eV DEI in Tables S-1 and 3, of 298/382 at 15-eV DEI in Tables 1 and 3).

Polymer- $V$ was chosen to further test the validity of the methodology by examining slightly different side chains. The nonyl and decyl groups in these copolymers are expected to behave nearly identically. Excellent agreement between experimental and calculated values for this monomer confirms these expectations.

The experimental data for Polymer-VI do not fit well with a random distribution model. There could be several reasons for this, most being related to the unusual ion chemistry of the dioxolane side chain, which makes ions derived from this compound extremely reactive by routes not available to the other polymers and for which the simple correction used may be a poor approximation. Note that the $15-\mathrm{eV}$ DEI spectra of Polymer-VI (Table S-7) do not show the protonated homotrimer $m / z 472$, and the proto-

Table 5. Distribution of monomers in the copolymers, based on 15-eV DEI data

\begin{tabular}{lccccc}
\hline & & & & \multicolumn{2}{c}{ Probability (experimental) } \\
\cline { 5 - 6 } Copolymer & Trimer $(m / z)$ & Calculated probability & Correction factor & Corrected & Uncorrected \\
\hline \hline Polymer-IV & 382 & 0.2456 & 12.60 & 0.2530 & 0.3584 \\
& 424 & 0.4469 & 18.41 & 0.4262 & 0.4122 \\
& 466 & 0.2595 & 24.22 & 0.2675 & 0.1971 \\
Polymer-V & 508 & 0.0481 & 30.03 & 0.0543 & 0.0323 \\
& 382 & 0.6786 & 12.60 & 0.6675 & 0.6102 \\
& 396 & 0.2841 & 10.40 & 0.2755 & 0.3051 \\
& 426 & 0.0359 & 8.20 & 0.0483 & 0.0678 \\
Polymer-VI & 456 & 0.0014 & 6.00 & 0.0088 & 0.0169 \\
& 508 & 0.1212 & 30.03 & 0.1163 & 0.1212 \\
& 522 & 0.3788 & 31.02 & 0.3604 & 0.3664 \\
& 536 & 0.3788 & 32.01 & 0.3874 & 0.3817 \\
& 550 & 0.1212 & 33.00 & 0.1358 & 0.1298 \\
\hline
\end{tabular}


nated trimers $m / z \quad 442$ and 412 are not abundant. Therefore, in the calculation of the substituent dissociation efficiency we had to use $m / z 456,426$, and 396, formed by loss of methyl radical from the radical cations $m / z 471,441$, and 411 , which are not observed in the mass spectra because of their instability. Such an approximation clearly adds to the error in the method.

\section{Conclusions}

Common features in the direct pyrolysis mass spectra of all the polymers discussed above are (1) trimers are the major products of thermal decomposition, along with minor amounts of monomers; (2) the trimers are observed as the protonated molecule and in some cases as the ammonia adduct, and as the radical cation and/or the product of its fast demethylation, depending upon the ionization conditions and the nature of the substituents; (3) the dominant fragmentation of the protonated trimers occurs via sequential losses of the substituents as alkenes, and this yields the key fragment, protonated cyanuric acid at $\mathrm{m} / \mathrm{z}$ 130; (4) other fragmentation processes include carbon-carbon and charge-remote $\mathrm{C}-\mathrm{C}$ cleavages within the substituent, which are diagnostic of branching in the alkyl chain; (5) protonated trimers bearing $n$-hexyl and 2,6-dimethylheptyl substituents show preferential loss of the larger alkyl group, whereas protonated trimers with 2,6-dimethylheptyl and 3,7-dimethyloctyl groups show preferential loss of the smaller alkyl group, both results being explained by preferential transfer of hydrogen bound to a tertiary carbon as opposed to a secondary carbon; (6) the protonated monomer is generated in part by fragmentation of the trimer, a process evident from parent spectra and the increase of the monomer/trimer ratio. with increased internal energy deposited upon ionization; (7) the protonated monomer is a substituted urea and accordingly fragments by $\mathrm{HNCO}$ loss to yield the protonated amine; and (8) the dioxolane-containing polymer shows fragmentation pathways different from those of the alkyl polymers because of the fragmentation-directing character of the ketal group.

A new approach to estimating the distribution of monomers along the copolymer chain is used in this study. With the possible exception of the copolymer containing the dioxolane substituent, the monomers in the copolymers are distributed randomly along the polymer chain.

\section{Supplementary Material}

Supplementary material for this article is available in photocopy form from the office of the Editor-in-Chief (see front of journal for address). Requests must in- clude complete title of article, names of authors, issue date, and page numbers. The supplementary material consists of Figure S-1, Tables S-1 through S-9, and Schemes S-I and S-II.

\section{Acknowledgments}

Work at Purdue University and the Polytechnic University was supported by the National Science Foundation (grants CHE 87-21768 and CHE 86-15872, respectively). Efforts at the Polytechnic were also aided by the donors of the Petroleum Research Fund, administered by the American Chemical Society, We thank Brian Shay and Tapio Kotiaho for helpful suggestions. M. F. acknowledges support from Conselhn Nacinnal de Desenvolvimento Científico e Tecnológico (CNPq), Brazil.

\section{References}

1. Shashoua, V. E.; Sweeny, W. E.; Teitz, R. F. I. Am. Chem. Soc. $1960,82,866$.

2. Libson, S.; Andreola, C.; Peterson, N. C.; Green, M. M. J. Am. Chem. Soc. 1989, 111, 8850; and references therein.

3. Bur, A.; Fetters, L. J. Chem. Rev. 1976, 76, $72 \%$.

4. Itou, T.; Teramoto, A. Macromolecules 1988, 21, 2225.

5. Durairaj, B.; Dimock, A. W.; Samulski, E. T.; Shaw, M. T. J. Polym. Sci. Part A: Polymer Chemistry, 1989, 27, 3211.

6. Lattimer, R. P.; Münster, H.; Budzikiewicz, H. Int. J. Mass Spectrom. lon Processes 1989, 90, 119.

7. Montaudo, G.; Scamporrino, E.; Vitalini, D. Macromolecules $1989,122,623$.

8. Bletsos, I. V.; Hercules, D. M.; Vanleyen, D; Benninghoven, A.; Karakatsanis, C. G.; Rieck, J. N. Anal. Chem. 1989, 61, 2142.

9. Macfarlane, R. D.; Hill, J. C.; Jacobs, D. L.; Phelps, R. G. In Mass Spectrometry in the Analysis of Large Molecules; McNeal, C. J., Ed.; Wiley: Chichester, 1986, p 1.

10. Barber, M.; Green, B. N. Rapid Contmun. Mass Spectrom. $1987,1,80$.

11. Karas, M.; Bahr, U.; Hillenkamp, F. Int. J. Mass Spectrom. Ion Processes 1989, 92, 231.

12. Cottrell, J. S.; Greathead, R. J. Mass Spectrom. Rev. 1986, 5, 215.

13. Amster, I. J.; McLafferty, F. W.; Castro, M. E.; Russell, D. H.; Cody, R. B. Jr.; Ghaderi, S. Anal. Chem. 1986, 58, 483.

14. Karas, M.; Bahr, U.; Ingendoh, A.; Hillenkamp, F. Angew. Chem. 1989, 101, 805

15. Kaiser, R. E.; Louris, J. N.; Amy, J. W.; Cooks, R. G. Rapid Commun. Mass Spectrom. 1989, 3, 225.

16. Zemany, P. D. Anal. Chem. 1952, 24, 1709.

17. Plage, B.; Schulten, H. R. Macromolecules 1988, 21, 2018.

18. Ballistreri, A.; Garozzo, D.; Maravigna, P.; Montaudo, G. J. Polym. Sci. Polym. Chem. Ed. 1987, 25, 1049.

19. Haken, J. K.; Tan, L. I. Polym. Sci. Polym. Chem. Ed. 1988, 26, 1315 .

20. Ballistreri, A.; Garozzo, D.; Giuffrida, M.; Montaudu, G. Polym. Degrad. Stab. 1986, 16, 337.

21. Montaudo, G.; Schamporrino, E.; Puglisi, G.; Vitalini, D. I. Polym. Sci. Polym. Chem. Ed. 1987, 25, 475.

22. Schulten, H. R.; Lattimer, R. P. Mass Spectrom. Rev. 1984, 3 231.

23. Snyder, A. P.; Kremer, J.H.; Meuzelaar, H. L. C.; Windig, W.; Taghizadeh, K. Anal. Chem. 1987, 59, 1945. 
24. Mantese, J. V.; Catalan, A. B.; Mance, A. M.; Hamdi, J. A.; Micheli, J. L.; Sell, J. A.; Meyer, M. S. Appl. Phys. Lett. 1988, 53, 1335.

25. Meuzelaar, H. L. C.; Windig, W.; Huff, S. M.; Richards, J. M. Anal. Chim. Acta 1986, 190, 119.

26. Cotter, R. J. Anal. Chem. 1980, 52, 1589A.

27. Pachuta, S. J.; Cooks, R. G. Chem. Rev. 1987, 87, 647.

28. Nuwaysir ${ }_{r}$ L. M.; Wilkins, C. L.; Simonsick, W. J. Ir. I. Am. Soc. Muss Spectrom. 1990, 1, 66 .

29. Busch, K. L.; Cooks, R. G. In Tandem Mass Spectrometry; McLafferty, F. W., Ed.; Wiley: New York, 1983; chap. 2.

30. Busch, K. I.; Glish, G. L.; McLuckey, S. A. Mass Spectrometry/Mass Spectrometry: Techniques and Applications of Tandem Mass Spectrometry; VCH Publishers: New York, 1988.

31. Hunt, D. F.; Bone, W. M.; Shabanowitz, J+; Rhodes, J.; Ballard, J. M. Anal. Chem. 1981, 53, 1704.

32. Bradley, C. V.; Williams, D. H.; Hanley, M. R. Biochem. Biophys. Res. Commun. 1982, 104, 1223.

33. Louris, J. N.; Wright, L. G.; Cuoks, R. G.; Schoen, A. E. Aral. Chem . 1985, 57, 2918.

34. Beaugrand, C.; Devant, G.; Jaouen, D.; Rolando, C. Int. J. Mass Spectrom. Ion Processes, in press.
35. Schwartz, J. C.; Schey, K. L.; Cooks, R. G. Int. J. Mass Spectrom. Ion Processes, 1990, 101, 1.

36. Green, M. M.; Gross, R. A.; Crosby, C. C. III; Schilling, F. C. Macromolecules 1987, $20,992$.

37. Green, M. M.; Reidy, M. P.; Johnson, R. D.; Darlino, G.; O'Leary, D. J.; Willson, G. J. Am. Chem. Soc. 1989, 111, 6452.

38. Budzikiewicz, H.; Dierassi, C.; Williams, D. H. Mass Spectrometry of Organic Compounds; Holden-Day: San Francisca, 1967; chapter 6, section 9.2, p 363.

39. Lyon, P. A.; Crow, F. W.; Tomer, K. B.; Gross, M. L. Anal. Chem. 1984, 56, 2278.

40. Jensen, N. J.; Tomer, K. B.; Gross, M. L. I. Am. Chem. Soc. 1985, 107, 1863.

41. Burinsky, D. J.; Campana, D. E.; Cooks, R. G. Int. J. Mass Spectrom. Ion Processes 1984, 62, 303.

42. McLafferty, F. W. Interpretation of Mass Spectra, 2nd ed.; W. A. Benjamin: London, $1973 ;$ p 62.

43. Budzikiewicz, H.; Djerassi, C.; Williams, D. H. Mass Spectrometry of Organic Compounds; Holden-Day: San Francisco, 1967; Chap. 6, Sec. 6.3, pp. 258-268. 